\title{
Associations between COVID-19 Risk Perceptions and Mental Health, Wellbeing, and
}

\section{Risk Behaviours}

Maddy L. Dyer, $\mathrm{PhD}^{1,2}$, Hannah M. Sallis, $\mathrm{PhD}^{1,2,3}$, Jasmine N. Khouja, $\mathrm{PhD}^{1,2}$, Sarah Dryhurst, $\mathrm{PhD}^{4}$, Marcus R. Munafò, $\mathrm{PhD}^{1,2,5}$

1: School of Psychological Science, University of Bristol, Bristol, UK.

2: Medical Research Council Integrative Epidemiology Unit at the University of Bristol, Bristol, UK.

3. Centre for Academic Mental Health, Population Health Sciences, Bristol Medical School, University of Bristol, Bristol, UK

4: Winton Centre for Risk and Evidence Communication, University of Cambridge, Cambridge, UK

5: National Institute for Health Research Bristol Biomedical Research Centre, University Hospitals Bristol NHS Foundation Trust, Bristol, UK.

Corresponding author: Maddy L. Dyer, School of Psychological Science, University of Bristol, 12a Priory Road, Bristol, BS8 1TU, UK. Email: maddy.dyer@bristol.ac.uk. ORCID: https://orcid.org/0000-0002-5924-4400.Twitter: @ MaddyLDyer.

Word Count: 7900 (5130 for main body; 2770 for references) 


\begin{abstract}
Background: Mental health has worsened, and substance use has increased for some people during the coronavirus (COVID-19) pandemic. Some cross-sectional studies suggest that higher COVID-19 risk perceptions are related to poorer mental health and greater risk behaviours (e.g., substance use). However, longitudinal and genetic data can help to support stronger inferences regarding whether these associations reflect causal pathways. Methods: Using cross-sectional, longitudinal, and polygenic risk score (PRS) data from the Avon Longitudinal Study of Parents and Children (ALSPAC), we examined cross-sectional and prospective longitudinal associations between COVID-19 risk perceptions and mental health, wellbeing, and risk behaviours. We used pandemic (April-July 2020) and pre-pandemic (2003-2017) data (ns = 233-5,115). Results: Higher COVID-19 risk perceptions were
\end{abstract} associated with anxiety (OR $2.78,95 \%$ confidence interval [CI] 2.20 to 3.52 ), depression (OR 1.65, 95\% CI 1.24 to 2.18), low wellbeing (OR $1.76,95 \%$ CI 1.45 to 2.13 ), and increased alcohol use (OR 1.46, 95\% CI 1.24 to 1.72). Higher COVID-19 risk perceptions were also associated with self-isolating given a suspected COVID-19 infection (OR 1.74, 95\% CI 1.13 to 2.68 ), and less face-to-face contact (OR $0.83,95 \%$ CI 0.70 to 0.98 ) and physical contact (OR $0.83,95 \%$ CI 0.68 to 1.00 ). Pre-pandemic anxiety (OR $1.64,95 \%$ CI 1.29 to 2.09 ) and low wellbeing (OR 1.41, 95\% CI 1.15 to 1.74 ) were associated with higher COVID-19 risk perceptions. The depression ( $b 0.21,95 \%$ CI 0.02 to 0.40$)$ and wellbeing $(b-0.29,95 \%$ CI 0.48 to -0.09$)$ PRS were associated with higher and lower COVID-19 risk perceptions, respectively. Conclusions: Poorer mental health and wellbeing are associated with higher COVID-19 risk perceptions, and longitudinal and genetic data suggest that they may play a causal role in COVID-19 risk perceptions.

Keywords: coronavirus, risk perception, health behaviour, mental health, wellbeing, ALSPAC 


\section{Introduction}

The coronavirus (COVID-19) pandemic was declared in March 2020 (World Health Organisation 2021a). As of November 2021, there have been over 250 million confirmed cases, including over 5 million deaths globally (World Health Organisation 2021b). The pandemic and mitigation measures have impacted mental health (Byrne, Barber, and Lim 2021); $60 \%$ of UK adults report that their mental health has deteriorated, and $36 \%$ report using alcohol or illegal drugs to cope (Mind 2020). Wellbeing has reduced, anxiety has almost doubled (from $13 \%$ to $24 \%$ ) (Kwong et al. 2020), and approximately $25 \%$ of people report drinking alcohol and smoking more (Garnett et al. 2021, Tzu-Hsuan Chen 2020). Risk perceptions are subjective judgements about the characteristics, severity, and probability of a risk (Darker 2013). They can influence emotions and behaviours (Ferrer and Klein 2015, Paek and Hove 2017), and impact how governments and individuals respond to the pandemic (McCloskey and Heymann 2020). COVID-19 risk perceptions (e.g., likelihood of infection, worries about infection) may have contributed to the changes in mental health, wellbeing, and risk behaviours observed during the pandemic.

Conversely, risk behaviours could also influence COVID-19 risk perceptions. According to self-perception theory, behaviours affect thoughts and attitudes (Bem 1972). People may adjust their perception of risk to align with their behaviour if they cannot (or choose not to) adjust their behaviour, in order to reduce cognitive dissonance (Festinger 1957). For example, going to work rather than self-isolating following a COVID-19 diagnosis (e.g., for financial reasons) may lead to reduced risk perceptions. Understanding COVID-19 risk perceptions and their possible bidirectional associations with mental health and risk behaviours is therefore crucial. This research has implications for risk communication and public health messaging during the current pandemic and future pandemics. 


\section{Mental Health and Wellbeing}

Cross-sectional studies have found associations between higher COVID-19 risk perceptions and poorer mental health (e.g., increased anxiety and depression) (Han et al. 2021, Li and Lyu 2020, Liu, Zhang, and Huang 2020, Yin et al. 2021, Zhong et al. 2021). However, the direction of the relationship is unclear in these studies. Poorer mental health and wellbeing may precede risk perceptions. Indeed, according to valence approaches, negative emotions lead to higher risk perceptions (Lerner and Keltner 2000). The authors of another cross-sectional study argued for this, reporting that anxiety and depression influences higher COVID-19 risk perceptions (Orte et al. 2020). However, longitudinal studies are required to better understand possible causal pathways.

\section{Smoking}

Similarly, the relationship between risk behaviours (e.g., smoking) and COVID-19 risk perceptions may be bidirectional. Smoking may lead to higher COVID-19 risk perceptions because smoking is a risk factor for COVID-19 disease progression, severity (Vardavas and Nikitara 2020, Li and Hua 2021, Clift et al. 2021), and transmission (Ahmed et al. 2020), and these findings have had media exposure. Conversely, early reports that smoking may be protective against COVID-19 infection also gained media attention, which may have had the opposite effect (van Westen-Lagerweij et al. 2021). COVID-19 risk perceptions may also influence smoking behaviours. For example, Jackson and colleagues (2020) found that higher COVID-19 risk perceptions were associated with smoking less than usual among smokers with post-16 qualifications. Higher COVID-19 risk perceptions were also associated with smoking more than usual, and these associations were stronger for smokers without post-16 qualifications than those with. Shepherd and colleagues (2021) found that COVID-19 worries were positively associated with coping motives for smoking 
and perceived barriers for smoking cessation. Smokers also report lower adherence to COVID-19 prevention guidelines than never smokers, despite greater worries about infection (Jackson et al. 2020).

\section{Electronic Cigarette Use}

As with the research on smoking, conflicting reports suggest that electronic cigarette (e-cigarette) use may be a risk factor for (Gaiha, Cheng, and Halpern-Felsher 2020) or a protective factor against (Majmundar et al. 2020) COVID-19 infection, which may influence risk perceptions and behaviours among e-cigarette users. For example, stronger beliefs that ecigarette users are at greater risk from COVID-19 are associated with more frequent ecigarette cessation considerations (Kelly, Pawson, and Vuolo 2020). Furthermore, more frequent e-cigarette use was also associated with reduced beliefs that e-cigarette users are at greater risk from COVID-19 (Kelly, Pawson, and Vuolo 2020). However, there is no clear evidence to support a causal relationship between e-cigarette use and COVID-19 infection (Farsalinos and Niaura 2021).

\section{Alcohol Use}

Although there is no clear evidence of an association between alcohol consumption and COVID-19 severity (Hamer et al. 2020, Li and Hua 2021), some suggest that alcohol use (Saengow, Assanangkornchai, and Casswell 2021) and misuse (Bailey, Samuelson, and Wyatt 2021) are probable risk factors for worse COVID-19 outcomes, which may influence risk perceptions and behaviours. For example, Panno and colleagues (2020) found an association between COVID-19 distress and alcohol problems. The relationship may depend on how risk perceptions are operationalised. For example, Alpers and colleagues (2021) found that COVID-19 economic (not health) worries were associated with increased drinking. 
Garnett and colleagues (2021) found stress about catching COVID-19, becoming seriously ill, and financial stress were associated with drinking more than usual. However, the former was also associated with drinking less. Therefore, higher COVID-19 risk perceptions may motivate some people to reduce the amount they drink, smoke, or use e-cigarettes due to health concerns, and motivate others to drink, smoke, or use e-cigarettes more as a coping strategy (Yingst et al. 2021).

\section{COVID-19 Risk and Protective Behaviours}

Risk perceptions are central to protection motivation theory, which explains how protective behaviours are initiated and maintained (Rogers 1975, Floyd, Prentice-Dunn, and Rogers 2000). Higher COVID-19 risk perceptions are associated with protective behaviours that reduce virus transmission, such as hand washing, social distancing, and wearing face coverings (Wise et al. 2020, Bruine de Bruin and Bennett 2020, Savadori and Lauriola 2020, Schneider et al. 2021, Dryhurst et al. 2020). However, they are also associated with stockpiling behaviours (Garbe, Rau, and Toppe 2020, Long and Khoi 2020), potentially leading to shortages (Abrams and Greenhawt 2020).

\section{Current Study}

Previous research on this topic has predominantly been cross-sectional. Although some researchers have investigated longitudinal predictors of COVID-19 risk perceptions (Schneider et al. 2021), to the best of our knowledge no studies have examined the role of mental health, wellbeing, and substance use as precursors. We were particularly interested in the question of whether poorer mental health and wellbeing may be causal risk factors for COVID-19 risk perceptions. Although observational data offer a relatively weak basis for causal inference, longitudinal data support somewhat stronger causal inference by providing 
clarity on the temporal relationship between exposures and outcomes. In addition, polygenic risk scores (PRS; single scores that capture genetic liability to a condition by combining multiple genetic variants) (Choi, Mak, and O'Reilly 2020) can also support stronger causal inference by reducing the potential for confounding. Because PRS are determined at conception and are stable over time, their association with an outcome should not be affected by confounders over the life course.

We examined the bidirectional associations between COVID-19 risk perceptions and mental health, wellbeing, and risk behaviours. First, we investigated cross-sectional associations between COVID-19 risk perceptions (exposures) and mental health (anxiety, depression), wellbeing, and risk behaviours (alcohol use, smoking, e-cigarette use, lack of self-isolating given a suspected COVID-19 infection, face-to-face and physical contact outside the household) (outcomes). Second, we investigated prospective longitudinal associations between pre-pandemic mental health, wellbeing, and risk behaviours (alcohol use, smoking, e-cigarette use) and early pandemic risk behaviours (lack of self-isolating, social contact) (exposures) and COVID-19 risk perceptions (outcomes). Third, we investigated whether genetic propensities for anxiety, depression, and wellbeing (exposures) are associated with COVID-19 risk perceptions (outcomes). We hypothesised that (1) COVID-19 risk perceptions would be positively associated with anxiety, depression, low wellbeing, alcohol use, and self-isolating, and negatively associated with social contact, (2) pre-pandemic anxiety, depression, low wellbeing and early pandemic self-isolating would be positively associated with COVID-19 risk perceptions, and pre-pandemic alcohol use and early pandemic social contact would be negatively associated with COVID-19 risk perceptions, and (3) anxiety and depression PRS and wellbeing PRS would be positively and negatively associated with COVID-19 risk perceptions, respectively. We had no directional hypotheses for smoking and e-cigarette use. 


\section{Methods}

\section{Design}

We conducted cross-sectional and prospective longitudinal analyses of secondary data from the Avon Longitudinal Study of Parents and Children (ALSPAC), a UK populationbased birth cohort study (Boyd et al. 2013, Fraser et al. 2013, Northstone et al. 2019). The sample was broadly representative of the region at the time (Boyd et al. 2013). Ethics approval was obtained from the ALSPAC Ethics and Law Committee and the Local Research Ethics Committees (http://www.bristol.ac.uk/alspac/researchers/research-ethics/). Informed consent for the use of data collected via questionnaires and clinics was obtained following recommendations of the ALSPAC Ethics and Law Committee. Consent for biological samples was collected in accordance with the Human Tissue Act (2004). Our study protocol was pre-registered on the Open Science Framework (https://osf.io/qan65/).

\section{Participants}

ALSPAC recruited pregnant women living in Avon with expected delivery dates between April 1991-December 1992, and 14,541 pregnancies were initially enrolled. We used data from mothers (G0) and the original children (G1; 'young people'). We could not include G0 partner data (mothers' partners who were predominantly males), as identities cannot be linked across questionnaires. For example, a partner completing a prepandemic questionnaire may not be the same partner completing a pandemic questionnaire. Data from G1 participants at $\geq 22$ years were collected and managed using REDCap (Harris et al. 2009). The ALSPAC study website contains the data dictionary and variable search tool (http://www.bristol.ac.uk/alspac/researchers/our-data). 


\section{Polygenic Risk Scores}

Summary statistics from genome-wide association studies (GWAS) for anxiety (Purves et al. 2020), depression (Howard et al. 2019), and wellbeing (Baselmans et al. 2019) were used to derive corresponding PRS among participants with genetic data. We calculated PRS using a threshold of $p<.05$ to increase the percentage of variance explained in each phenotype while trying to minimise pleiotropy. This increased our statistical power to detect an effect, given our small sample size, but potentially at the expense of specificity. Genotype data were available for 8,196 mothers and 8,237 young people. Full details are available in the Supplementary Material.

\section{Self-Report Measures}

The data dictionary describes all self-report measures (Supplementary Table S1). Variables were binary, except for the continuous COVID-19 risk perception variables that were used to test hypothesis 3. Time points of pre-pandemic measures (2003-2017) were selected based on the most recent and valid measures available (i.e., standardised scales preferred over single items). Therefore, follow-up periods varied from 3-17 years (Supplementary Figure S1). Separate variables were created for mothers, young people, and the whole sample combined, where possible.

\section{Risk Perceptions}

COVID-19 risk perceptions (five variables) were assessed in ALSPAC's second COVID-19 questionnaire (26.05.2020 to 05.07.2020) (Northstone, Smith, et al. 2020). COVID-19 cognitive risk perceptions (i.e., thought-related risk perceptions) were measured by three summed items that assessed perceptions of COVID-19 impact, likelihood of infection, and severity of infection from 1 'strongly disagree' to 5 'strongly agree'. COVID- 
19 affective risk perceptions (i.e., feeling-related risk perceptions) were measured by five summed items that assessed worries about COVID-19 infection (with respect to themselves [self] or other people [others]), transmission, and death (self/others) from 1 'not at all worried' to 5 'very worried'. A holistic measure of COVID-19 risk perceptions was calculated by summing all eight items (mothers: Cronbach's $\alpha=.82$; young people: Cronbach's $\alpha=.80$ ). COVID-19 self- and other-risk perceptions combined items concerning oneself versus others, respectively. Binary variables were created by dichotomising continuous variables at the median. These binary variables were exposure variables for hypothesis 1 , and outcome variables for hypothesis 2 . The continuous variables were outcome variables for hypothesis 3 .

\section{Mental Health and Wellbeing}

Outcomes: Current generalised anxiety disorder (GAD), depression, and wellbeing were assessed in the second COVID-19 questionnaire, using the Generalised Anxiety Disorder Assessment (GAD-7) (Spitzer et al. 2006), Short Mood and Feelings Questionnaire (SMFQ) (Angold et al. 1995), and Warwick-Edinburgh Mental Wellbeing Scale (WEMWBS) (Tennant et al. 2007), respectively. These measures have recommended binary cut-offs for examining the proportion of individuals with probable GAD ( $\geq 10)$ (Kroenke et al. 2007), likely depression ( $\geq 12$ ) (Child Outcomes Research Consortium 2021, Jarbin et al. 2020), and low wellbeing $(\leq 40)$ (Warwick Medical School 2021).

Exposures: Pre-pandemic anxiety, depression, and low wellbeing were assessed at different time points (2003-2017). For mothers, single items separately assessed prepandemic anxiety, depression, and low wellbeing (no/yes). For young people, pre-pandemic GAD and depression (mild episode) (no/yes) were derived from the Clinical Interview

Schedule - Revised (CIS-R), and low wellbeing (no/yes) was derived from the WEMWBS. 


\section{Risk Behaviours}

Outcomes: High-risk drinking (no/yes), increased alcohol use since lockdown (no/yes), increased smoking/e-cigarette use (no/yes), self-isolating given a suspected or confirmed COVID-19 infection (no/yes), and face-to-face and physical contact with individuals outside one's household (none/at least one person) were assessed in the second COVID-19 questionnaire. The Alcohol Use Disorders Identification Test - Consumption (AUDIT-C) has a recommended cut-off for high-risk drinking $(\geq 5)$ (Kelly et al. 2009).

Exposures: Pre-pandemic high-risk drinking, smoking (no/yes), and e-cigarette use (no/yes; young people only), were assessed at different time points (2012-2017). Early pandemic risk/protective behaviours (self-isolating, social contact) were assessed in the first COVID-19 questionnaire (09.04.2020 to 15.05.2020) (Northstone, Howarth, et al. 2020).

\section{Covariates}

Age, sex, education, and keyworker status (partially adjusted models), and additionally, pre-pandemic anxiety, depression, high-risk drinking, smoking, and early pandemic suspected COVID-19 infection (fully adjusted models), were included as covariates. Covariates were selected based on their a priori relevance and/or their associations with risk perceptions, mental health, and/or risk behaviours in the literature (i.e., their potential to be a confounder). By using a categorical age variable (Supplementary Table S2), the age adjustment accounted for the bimodal age distribution.

\section{Statistical Analyses}

Analyses were conducted in Stata SE (Version 15.0). We used logistic regression to examine cross-sectional and prospective longitudinal associations (hypotheses 1 and 2). We 
assessed the impact of potential confounding by comparing unadjusted and adjusted models. We planned to use multiple regression for hypothesis 2 and model all exposures simultaneously; however, to avoid reductions in sample size (due to pre-pandemic measures at different time points), we ran separate regressions for each exposure. We used linear regression for the PRS analyses (hypothesis 3) and adjusted for the top ten genetic principal components of ancestry.

We analysed data from the whole sample, accounting for relatedness (i.e., by specifying that the standard errors allow for intragroup correlation, relaxing the independence of observations assumption). We also stratified analyses by generational cohort to explore differences. For example, older age is associated with higher risk perceptions of dying from COVID-19, but lower risk perceptions of being infected, and lower depression and anxiety (Bruine de Bruin and Bennett 2020). We performed complete case analyses for hypotheses 1 and 2, to tease apart possible effects of confounding versus reductions in sample size between unadjusted and adjusted models. We report fully adjusted results for COVID-19 holistic risk perceptions unless stated otherwise. Results are interpreted in terms of the strength of evidence against the null hypothesis (e.g., $p<.05$ provides modest evidence whilst $p<.001$ provides strong evidence), direction of effect estimates, and consistency of evidence across sensitivity analyses (Sterne and Davey Smith 2001).

\section{Results}

\section{Participant Characteristics}

A total of 5,319 mothers and young people completed the second COVID-19 questionnaire, and 5,064 had complete data on COVID-19 risk perceptions. Sample sizes ranged from 413-5,115 for cross-sectional analyses, 233-4,243 for prospective longitudinal analyses, and 3,615-3,672 for PRS analyses. Age ranged from 27-29 years for young people 
$(M=27.7, S D=0.6)$, and from $44-72$ years for mothers $(M=58.1, S D=4.4) ; 85 \%$ of the whole sample were female ( $71 \%$ of young people), and $98 \%$ were of White ethnicity. Participant characteristics are summarised in Supplementary Tables S2-S7.

\section{Cross-Sectional Associations (Hypothesis 1)}

Whole Sample

Cross-sectional results are presented in Table 1 and Figure 1. There was strong evidence of a positive association between COVID-19 risk perceptions and GAD (OR 2.78, 95\% confidence interval $[\mathrm{CI}] 2.20$ to $3.52, p<.001)$, depression (OR $1.65,95 \% \mathrm{CI} 1.24$ to $2.18, p<.001$ ), and low wellbeing (OR 1.76, 95\% CI 1.45 to $2.13, p<.001$ ). Associations were consistent across risk perception dimensions, except cognitive, where associations with depression and low wellbeing were attenuated in fully adjusted models.

There was no clear evidence of an association between COVID-19 risk perceptions and high-risk drinking (OR $0.95,95 \%$ CI 0.79 to $1.13, p=.54$ ), or increased smoking/ecigarette use (OR $1.14,95 \%$ CI 0.72 to $1.80, p=.59)$. There was strong evidence that COVID-19 risk perceptions and increased alcohol use were positively associated (OR 1.46, 95\% CI 1.24 to $1.72, p<.001$ ), except for cognitive risk perceptions, which was not robust to adjustment for confounders. There were positive associations between some COVID-19 risk perceptions (holistic, cognitive) and self-isolating given a suspected COVID-19 infection (OR $1.74,95 \%$ CI 1.13 to $2.68, p=.012$ ). There were negative associations between some COVID-19 risk perceptions (holistic, affective, self) and face-to-face contact (OR 0.83, 95\% CI 0.70 to $0.98, p=.027)$, and all COVID-19 risk perceptions and physical contact (OR 0.83, $95 \%$ CI 0.68 to $1.00, p=.049)$.

[Table 1 and Figure 1 near here]. 
Sensitivity Analyses

Results stratified by cohort are presented in Supplementary Tables S8-S9. Results were largely similar across generations, except for increased alcohol use (positive associations for mothers only), and face-to-face contact (some negative associations for mothers only). Complete case results are presented in Supplementary Tables S10-S12. There were strong positive associations between COVID-19 risk perceptions (except cognitive) and GAD, depression, low wellbeing, and increased alcohol use (Table S10). Positive associations between some risk perceptions and self-isolating remained, as did negative associations between some risk perceptions and social contact.

\section{Prospective Longitudinal Associations (Hypothesis 2)}

Whole Sample

Results from prospective analyses with pre-pandemic measures are presented in Table 2 and Figure 2. There was strong evidence that pre-pandemic anxiety (OR 1.64, 95\% CI 1.29 to $2.09, p<.001$ ) and low wellbeing (OR $1.41,95 \%$ CI 1.15 to $1.74, p=.001$ ) were positively associated with COVID-19 risk perceptions, except cognitive. There was no clear evidence that pre-pandemic depression was associated with COVID-19 risk perceptions (OR $0.94,95 \%$ CI 0.73 to $1.22, p=.65)$. Pre-pandemic high-risk drinking was negatively associated with COVID-19 self-risk perceptions only (OR 0.78, 95\% CI 0.65 to $0.92, p=$ .004). There was no clear evidence that pre-pandemic smoking (OR 1.14, 95\% CI 0.72 to $1.80, p=.59)$ or e-cigarette use (OR 1.49, 95\% CI 0.72 to 3.09, $p=.29$; Supplementary Table S13) were associated with COVID-19 risk perceptions.

[Table 2 and Figure 2 near here]. 
Results from prospective analyses with early pandemic measures are presented in Table 3 and Figure 2. There was no clear evidence that early pandemic self-isolating given a suspected COVID-19 infection (OR 1.26, 95\% CI 0.64 to 2.48, $p=.50$ ), face-to-face contact (OR $0.93,95 \%$ CI 0.78 to $1.11, p=.43$ ), or physical contact (OR $0.93,95 \%$ CI 0.73 to 1.19 , $p=.56)$ were associated with later COVID-19 risk perceptions.

[Table 3 near here].

\section{Sensitivity Analyses}

Results stratified by cohort are presented in Supplementary Tables S13-S16. Results were largely similar across generations, except for pre-pandemic high-risk drinking (negative associations with self-risk perceptions for young people only) and smoking (positive associations with self-risk perceptions for mothers only). Results from the complete case analyses are presented in Supplementary Tables S17-S22. Positive associations between prepandemic anxiety and low wellbeing and COVID-19 risk perceptions remained, and the negative association between pre-pandemic high-risk drinking and COVID-19 self-risk perceptions remained (Supplementary Table S17).

\section{Polygenic Risk Score Associations (Hypothesis 3)}

There was no clear evidence that the anxiety PRS was associated with COVID-19 risk perceptions $(b 0.12,95 \% \mathrm{CI}-0.08$ to $0.31, p=.24)$. The depression PRS was positively associated with COVID-19 holistic, affective, and other-risk perceptions ( $b 0.21,95 \% \mathrm{CI}$ 0.02 to $0.40, p=.029$ ), whilst the wellbeing PRS was negatively associated with COVID-19 
risk perceptions (except cognitive) $(b-0.29,95 \%$ CI -0.48 to $-0.09, p=.004)$. PRS results are shown in Table 4.

[Table 4 near here].

\section{Attrition}

Post hoc analyses to explore differential attrition revealed that the anxiety and depression PRS were negatively associated with completion of the first COVID-19 questionnaire (OR 0.92, 95\% CI 0.89 to $0.96, p<.001$; OR 0.93, 95\% CI 0.90 to $0.97, p<$ .001 , respectively) and the second COVID-19 questionnaire (OR $0.95,95 \%$ CI 0.92 to $0.99, p$ $=.02$; OR $0.95,95 \%$ CI 0.91 to $0.98, p=.006$, respectively). The wellbeing PRS was positively associated with completion of the first (OR $1.12,95 \%$ CI 1.07 to $1.16, p<.001$ ) and second (OR 1.10, 95\% CI 1.05 to $1.14, p<.001)$ COVID-19 questionnaires.

\section{Discussion}

In support of hypothesis 1, higher COVID-19 risk perceptions (except cognitive) were cross-sectionally associated with higher anxiety, depression, lower wellbeing, and increased alcohol use. For some risk perception measures, higher COVID-19 risk perceptions were associated with self-isolating given a suspected COVID-19 infection, and less social contact. Our findings support studies that have found associations between higher COVID-19 risk perceptions and worse mental health (Han et al. 2021, Li and Lyu 2020, Yin et al. 2021, Zhong et al. 2021), drinking more than usual (Garnett et al. 2021), and increased COVID-19 prevention behaviours (Dryhurst et al. 2020, Schneider et al. 2021). COVID-19 risk perceptions were not associated with high-risk drinking or increased smoking/e-cigarette use. 
In support of hypothesis 2, pre-pandemic anxiety and low wellbeing were associated with higher COVID-19 risk perceptions (except cognitive), indicating a temporal relationship consistent with a causal effect of anxiety and wellbeing on later risk perceptions. However, pre-pandemic depression was not clearly associated with COVID-19 risk perceptions (comorbid anxiety was likely driving unadjusted associations). Pre-pandemic high-risk drinking was associated with lower COVID-19 self-risk perceptions. Pre-pandemic smoking and e-cigarette use, and early pandemic self-isolating and social contact were not associated with COVID-19 risk perceptions.

There were differences between COVID-19 risk perception dimensions. Mental health and wellbeing were associated with affective (not cognitive) dimensions, perhaps unsurprisingly as worries are a common feature across anxiety disorders and depression (Rabner et al. 2017). Pre-pandemic anxiety was also more strongly associated with COVID19 worries than pre-pandemic depression, a distinction supported elsewhere (Wright, Steptoe, and Fancourt 2021). Cognitive models suggest that anxiety is future oriented and predictive of threat, whereas depression is past oriented (Dobson 1985), which may explain these differences. Odds of increased alcohol use (measure excluded non-drinkers) were higher among individuals with higher risk perceptions, suggesting a possible drinking to cope mechanism.

In support of hypothesis 3, the wellbeing PRS was negatively associated with COVID-19 risk perceptions (except cognitive), and the depression PRS was positively associated with COVID-19 risk perceptions (except cognitive and self). However, there was no clear evidence of an association for the anxiety PRS. This could be due to limited statistical power; the anxiety PRS was the weakest genetic instrument and explained less variance in the phenotype compared to the depression and wellbeing PRS. Stronger instruments could be created as larger GWAS of more precisely measured phenotypes 
become available. Furthermore, cohorts with larger samples than ALSPAC would have more power to detect genetic associations. The lack of clear statistical evidence for self-reported pre-pandemic depression (versus depression PRS) may be due to measurement differences. The self-report measure represented participants who reported a mild depressive episode, whereas the genome-wide meta-analysis of depression included individuals reporting clinical diagnoses of, and meeting standard criteria for, major depressive disorder. Furthermore, given that anxiety and depression are frequently comorbid (Lamers et al. 2011), there may have been statistical overadjustment in models where they were included as covariates.

Results were largely similar across generational cohorts, although exploratory analyses suggested some differences across age groups. First, among mothers, COVID-19 risk perceptions and increased alcohol use were cross-sectionally positively associated, but we did not see evidence of this among young people. This is consistent with evidence of increased alcohol consumption among older (versus younger) individuals during the pandemic (Sallie et al. 2020), and drinking to cope is common among older adults (Gilson, Bryant, and Judd 2017). However, differences may have been driven by biological sex, because older participants were mothers (i.e., categorised as females). For example, women are more likely than men to drink to cope (Peltier et al. 2019). Second, some negative associations between COVID-19 risk perceptions and face-to-face contact only held in mothers, which may be explained by age/employment differences; $20 \%$ of mothers were retired, potentially making reduction of social contact easier. Third, pre-pandemic high-risk drinking was negatively associated with COVID-19 self-risk perceptions in young people only. It is plausible that people who engage in any risky behaviours perceive lower risks to themselves generally. But this association may not have held in older adults, who may be aware of the disproportionate negative effects of COVID-19 on their health (Mueller, McNamara, and Sinclair 2020). Finally, pre-pandemic smoking was positively associated 
with COVID-19 self-risk perceptions in mothers only, again possibly due to age-related risk. Stratified analyses were exploratory; future studies could test the robustness of these findings, which should be considered hypothesis-generating, in other samples.

Our study has limitations. First, the sample was predominantly female and of White ethnicity, which may impact the generalisability of results. Males report lower COVID-19 risk perceptions (Rodriguez-Besteiro et al. 2021, Dryhurst et al. 2020). However, we did adjust for biological sex, and we also presented results separately for mothers and young people, with the latter cohort having a greater proportion of males than in the combined cohort. Furthermore, people from Black, Asian, and Minority Ethnic communities are nearly twice as likely to die from COVID-19 than people of White ethnicity (White and Ayoubkhani 2020). Therefore, ethnicity may influence COVID-19 risk perceptions. Second, we combined two generational cohorts, which resulted in a bimodal age distribution. However, we adjusted for age and additionally we conducted analyses stratified by generational cohort. Third, we used pandemic data from one time point, which cannot capture changes as a pandemic evolves (Zhong et al. 2021, Brown, Coventry, and Pepper 2021). Changes in policies, vaccine development, knowledge, and personal experiences may influence risk perceptions and behaviours. Longitudinal studies with repeated assessments during and after pandemics are required to examine bidirectionality. Fourth, we adjusted for suspected COVID-19 infection because this is associated with lower risk perceptions and higher risk behaviours (Smith et al. 2020), however we could not include COVID-19 severity (hospital admission), which likely influences risk perceptions, due to participant disclosure risk. Therefore, there may be unmeasured confounding. Fifth, risk perception is a heterogeneous construct, and there is no standardised measure (Lanciano et al. 2020). Future studies should also include work/economic and social/relationship risk perceptions to reflect the pervasive impact of a pandemic. For example, work/economic COVID-19 risk perceptions are reportedly higher 
than those concerning health (Lanciano et al. 2020), and increased drinking is more frequent among people reporting economic (versus health) COVID-19 worries (Alpers et al. 2021). Sixth, there was evidence of differential attrition; people at a higher risk of anxiety and depression were less likely to have completed the COVID-19 questionnaires. The properties of these missing individuals remain unknown, and hence the bias is difficult to predict. However, this pattern of attrition may have attenuated our associations (e.g., for the anxiety PRS) towards the null (i.e., the true associations may be stronger than reported). Finally, smoking and e-cigarette use were conflated in the COVID-19 questionnaires but should be examined separately. Smokers with higher COVID-19 risk perceptions could have switched to using e-cigarettes, but this would not have been captured in the data.

Our study also has strengths. First, longitudinal data helped to determine the temporal direction of associations, extending findings from previous cross-sectional studies, although cause and effect cannot be established in observational studies. Second, we adjusted analyses for various potential covariates, to reduce the chance of reverse causation and confounding bias. Third, the large sample (albeit relatively small for exploring genetic associations) increased the power to detect associations in the observational analyses. Fourth, we conducted extensive complete case analyses to help tease apart the influence of sample size reductions and confounding. Finally, genetic analyses were consistent with the possibility that low wellbeing and depression may play a causal role in COVID-19 risk perceptions. Although this research question was causal, and we used the best data and methods available to us to answer this, inferences must be cautious. Mendelian Randomization (MR) analyses in larger samples are needed to test the causality question fully. Genetic variants can be used in MR analyses to provide (under certain assumptions) unconfounded causal estimates (Davey Smith and Ebrahim 2003). MR typically uses single-nucleotide polymorphisms (SNPs) that reach genome-wide significance (i.e., $p<5 \times 10^{-8}$ ) (Richardson et al. 2019). PRS can be 
derived using more liberal $p$-value thresholds, which capture more genetic variance but can reduce the specificity of the PRS to the exposure of interest (e.g., by including more variants with pleiotropic effects).

COVID-19 risk perceptions were associated with poorer mental health, lower wellbeing, and increased alcohol use, and pre-pandemic anxiety and low wellbeing increased COVID-19 risk perceptions. This is concerning, given the increase in alcohol-related deaths in 2020 (Holmes and Angus 2021), and because worries about adversities can be as detrimental for mental health as actually experiencing adversities (Wright, Steptoe, and Fancourt 2021). However, some risk perceptions were also associated with COVID-19 prevention behaviours. A balanced approach to risk communication and public health messaging, in the context of the current pandemic and during future pandemics, is therefore required. As well as promoting public awareness of pandemic-related physical health risks to maintain rational risk perceptions and adherence to government guidelines, political and public health officials must also promote mental health and wellbeing for example by providing reassurance, adaptive coping strategies, and remote interventions to help people manage their worries (Zhong et al. 2021, Orte et al. 2020, Han et al. 2021, Bruine de Bruin and Bennett 2020). COVID-19 will be prevalent for years to come, with many scientists predicting that the virus that causes COVID-19 (SARS-CoV-2) will become endemic (Phillips 2021, Li et al. 2020). Furthermore, these findings about the interplay between COVID-19 risk perceptions, mental health, wellbeing, and risk behaviours will be valuable for future pandemics, informing broader pandemic preparedness efforts.

\section{Conclusions}

Higher COVID-19 risk perceptions were associated with anxiety, depression, low wellbeing, increased alcohol use, and COVID-19 prevention behaviours. Pre-pandemic 
anxiety and low wellbeing were associated with higher COVID-19 risk perceptions, and prepandemic high-risk drinking was associated with lower COVID-19 risk perceptions regarding oneself. Associations were most robust for anxiety and low wellbeing given the consistency across risk perception dimensions (except cognitive), cross-sectional and prospective analyses, and complete case analyses. Genetic analyses were consistent with the possibility that low wellbeing and depression may play a causal role in COVID-19 risk perceptions, but formal MR analyses in larger samples are warranted. These findings have implications for the understanding and management of COVID-19 in the long-term, and of future pandemics. 
Acknowledgements: We are extremely grateful to all the families who took part in this study, the midwives for their help in recruiting them, and the whole ALSPAC team, which includes interviewers, computer and laboratory technicians, clerical workers, research scientists, volunteers, managers, receptionists, and nurses. We would also like to thank Dr Anna Blackwell for some early comments on the protocol.

Disclosure statement: No potential competing interest was reported by the authors.

Funding: This research was funded in whole, or in part, by the Wellcome Trust (WT). For the purpose of Open Access, the author has applied a CC BY public copyright licence to any Author Accepted Manuscript version arising from this submission. The UK Medical Research Council (MRC) and WT (217065/Z/19/Z) and the University of Bristol (UoB) provide core support for ALSPAC. This publication is the work of the authors, and they will serve as guarantors for the contents of this paper. MLD, HMS, JNK and MRM are members of the MRC Integrative Epidemiology Unit (MRC IEU) at the UoB (MC_UU_00011/7). HMS is also supported by the European Research Council (758813 MHINT). This work is supported by the NIHR Biomedical Research Centre at University Hospitals Bristol NHS Foundation Trust and the UoB. The views expressed in this publication are those of the author(s) and not necessarily those of the NHS, the National Institute for Health Research or the Department of Health and Social Care. JNK is supported by Cancer Research UK (C18281/A29019). SD is funded by the Winton Centre for Risk and Evidence Communication which is supported by the David and Claudia Harding Foundation. A comprehensive list of grants funding is available on the ALSPAC website (http://www.bristol.ac.uk/alspac/external/documents/grant-acknowledgements.pdf). This research was specifically funded by the WT and MRC UoB Faculty Research Director's 
Discretionary Fund, and the Elizabeth Blackwell Institute (EBI) for Research (102215/2/13/2), the MRC (MR/L022206/1), Cancer Research UK (C54841/A20491), EBI and WT (PSYC.RJ6220; SSCM.RD1809), the National Institutes of Health (PD301198SC101645), and the WT (WT088806). GWAS data was generated by Sample Logistics and Genotyping Facilities at Wellcome Sanger Institute and LabCorp (Laboratory Corporation of America) using support from 23andMe.

Contributors: MLD wrote the study protocol and co-designed the study with all authors. HMS extracted the genetic data and created the polygenic risk scores. MLD extracted the self-report data, cleaned the data, and performed all the analyses. HMS and JNK performed quality control checks of data extraction, data cleaning, and analysis code. All authors discussed and interpreted the results. MLD wrote the manuscript with contributions from all authors. All authors approved the final version.

Data availability statement: The analysis code is available from the University of Bristol's Research Data Repository (http://data.bris.ac.uk/data/), DOI: (after peer review). GWAS summary statistics used to create the PRS are available from the original publications. The informed consent obtained from ALSPAC participants does not allow the data to be made freely available through any third party maintained public repository. However, data used for this submission can be made available on request to the ALSPAC Executive. The ALSPAC data management plan describes in detail the policy regarding data sharing, which is through a system of managed open access. Full instructions for applying for data access can be found here: http://www.bristol.ac.uk/alspac/researchers/access/. The ALSPAC study website contains details of all the data that are available (http://www.bristol.ac.uk/alspac/researchers/our-data/). 


\section{References}

Abrams, E. M., and M. Greenhawt. 2020. "Risk communication during COVID-19." $J$ Allergy Clin Immunol Pract 8 (6):1791-1794. doi: 10.1016/j.jaip.2020.04.012.

Ahmed, N., A. Maqsood, T. Abduljabbar, and F. Vohra. 2020. "Tobacco smoking a potential risk factor in transmission of COVID-19 infection." Pak J Med Sci 36 (COVID19S4):S104-S107. doi: 10.12669/pjms.36.COVID19-S4.2739.

Alpers, S. E., J. C. Skogen, S. Maeland, S. Pallesen, A. K. Rabben, L. H. Lunde, and L. T. Fadnes. 2021. "Alcohol consumption during a pandemic lockdown period and change in alcohol consumption related to worries and pandemic measures." Int J Environ Res Public Health 18 (3). doi: 10.3390/ijerph18031220.

Angold, A., E. J. Costello, S. C. Messer, and A. Pickles. 1995. "Development of a short questionnaire for use in epidemiological studies of depression in children and adolescents." International Journal of Methods in Psychiatric Research 5 (4):237249.

Bailey, K. L., D. R. Samuelson, and T. A. Wyatt. 2021. "Alcohol use disorder: A pre-existing condition for COVID-19?" Alcohol 90:11-17. doi: 10.1016/j.alcohol.2020.10.003.

Baselmans, B. M. L., R. Jansen, H. F. Ip, J. van Dongen, A. Abdellaoui, M. P. van de Weijer, Y. Bao, M. Smart, M. Kumari, G. Willemsen, J. J. Hottenga, Bios consortium, Consortium Social Science Genetic Association, D. I. Boomsma, E. J. C. de Geus, M. G. Nivard, and M. Bartels. 2019. "Multivariate genome-wide analyses of the wellbeing spectrum." Nat Genet 51 (3):445-451. doi: 10.1038/s41588-018-0320-8.

Bem, D.J. 1972. "Self-Perception Theory." Advances in Experimental Social Psychology 6:1-62. doi: https://doi.org/10.1016/S0065-2601(08)60024-6.

Boyd, A., J. Golding, J. Macleod, D. A. Lawlor, A. Fraser, J. Henderson, L. Molloy, A. Ness, S. Ring, and G. Davey Smith. 2013. "Cohort Profile: the 'children of the 90s'--the 
index offspring of the Avon Longitudinal Study of Parents and Children." International Journal Epidemiology 42 (1):111-27. doi: 10.1093/ije/dys064.

Brown, R., L. Coventry, and G. Pepper. 2021. "COVID-19: the relationship between perceptions of risk and behaviours during lockdown." Z Gesundh Wiss:1-11. doi: 10.1007/s10389-021-01543-9.

Bruine de Bruin, W., and D. Bennett. 2020. "Relationships between initial COVID-19 risk perceptions and protective health behaviors: A national survey." Am J Prev Med 59 (2):157-167. doi: 10.1016/j.amepre.2020.05.001.

Byrne, A., R. Barber, and C.H. Lim. 2021. "Impact of the COVID-19 pandemic - a mental health service perspective." Progress in Neurology and Psychiatry 25 (2):27-33. doi: https://doi-org.bris.idm.oclc.org/10.1002/pnp.708.

Child Outcomes Research Consortium. 2021. "Mood and Feelings Questionnaire (MFQ)." https://www.corc.uk.net/outcome-experience-measures/mood-and-feelingsquestionnaire-mfq/.

Choi, S. W., T. S. Mak, and P. F. O'Reilly. 2020. "Tutorial: a guide to performing polygenic risk score analyses." Nat Protoc 15 (9):2759-2772. doi: 10.1038/s41596-020-0353-1.

Clift, A. K., A. von Ende, P. S. Tan, H. M. Sallis, N. Lindson, C. A. C. Coupland, M. R. Munafo, P. Aveyard, J. Hippisley-Cox, and J. C. Hopewell. 2021. "Smoking and COVID-19 outcomes: an observational and Mendelian randomisation study using the UK Biobank cohort." Thorax. doi: 10.1136/thoraxjnl-2021-217080.

Darker, C. 2013. Risk Perception. In Encyclopedia of Behavioral Medicine, edited by Gellman M.D. and Turner J.R. New York: Springer.

Davey Smith, G., and S. Ebrahim. 2003. "'Mendelian randomization': can genetic epidemiology contribute to understanding environmental determinants of disease?" Int J Epidemiol 32 (1):1-22. doi: 10.1093/ije/dyg070. 
Dobson, K.S. 1985. "The relationship between anxiety and depression." Clinical Psychology Review 5 (4):307-324. doi: https://doi.org/10.1016/0272-7358(85)90010-8.

Dryhurst, S., C.R. Schneider, J. Kerr, A.L.J Freeman, G. Recchia, A.M. van der Bles, D. Spiegelhalter, and S. van der Linden. 2020. "Risk perceptions of COVID-19 around the world." Journal of Risk Research. doi: 10.1080/13669877.2020.1758193.

Farsalinos, K., and R. Niaura. 2021. "E-cigarette use and COVID-19: Questioning data reliability." J Adolesc Health 68 (1):213. doi: 10.1016/j.jadohealth.2020.09.012.

Ferrer, R., and W. M. Klein. 2015. "Risk perceptions and health behavior." Curr Opin Psychol 5:85-89. doi: 10.1016/j.copsyc.2015.03.012.

Festinger, L. 1957. A theory of cognitive dissonance. Stanford, CA: Stanford University Press.

Floyd, D. L., S. Prentice-Dunn, and R. W. Rogers. 2000. "A meta-analysis of research on Protection Motivation Theory." Journal of Applied Social Psychology 30 (2):407429. doi: https://doi.org/10.1111/j.1559-1816.2000.tb02323.x.

Fraser, A., C. Macdonald-Wallis, K. Tilling, A. Boyd, J. Golding, G. Davey Smith, J. Henderson, J. Macleod, L. Molloy, A. Ness, S. Ring, S. M. Nelson, and D. A. Lawlor. 2013. "Cohort Profile: the Avon Longitudinal Study of Parents and Children:

ALSPAC mothers cohort." International Journal of Epidemiology 42 (1):97-110. doi: 10.1093/ije/dys066.

Gaiha, S. M., J. Cheng, and B. Halpern-Felsher. 2020. "Association between youth smoking, electronic cigarette use, and COVID-19." J Adolesc Health 67 (4):519-523. doi: 10.1016/j.jadohealth.2020.07.002.

Garbe, L., R. Rau, and T. Toppe. 2020. "Influence of perceived threat of Covid-19 and HEXACO personality traits on toilet paper stockpiling." PLoS One 15 (6):e0234232. doi: 10.1371/journal.pone.0234232. 
Garnett, C., S. Jackson, M. Oldham, J. Brown, A. Steptoe, and D. Fancourt. 2021. "Factors associated with drinking behaviour during COVID-19 social distancing and lockdown among adults in the UK." Drug Alcohol Depend 219:108461. doi: 10.1016/j.drugalcdep.2020.108461.

Gilson, K. M., C. Bryant, and F. Judd. 2017. "Understanding older problem drinkers: The role of drinking to cope." Addict Behav 64:101-106. doi: 10.1016/j.addbeh.2016.08.032.

Hamer, M., M. Kivimaki, C. R. Gale, and G. D. Batty. 2020. "Lifestyle risk factors, inflammatory mechanisms, and COVID-19 hospitalization: A community-based cohort study of 387,109 adults in UK." Brain Behav Immun 87:184-187. doi: 10.1016/j.bbi.2020.05.059.

Han, Q., B. Zheng, M. Agostini, J. J. Belanger, B. Gutzkow, J. Kreienkamp, A. M. Reitsema, J. A. van Breen, P. Collaboration, and N. P. Leander. 2021. "Associations of risk perception of COVID-19 with emotion and mental health during the pandemic." $J$ Affect Disord 284:247-255. doi: 10.1016/j.jad.2021.01.049.

Harris, P. A., R. Taylor, R. Thielke, J. Payne, N. Gonzalez, and J. G. Conde. 2009. "Research electronic data capture (REDCap)--a metadata-driven methodology and workflow process for providing translational research informatics support." J Biomed Inform 42 (2):377-81. doi: 10.1016/j.jbi.2008.08.010.

Holmes, J., and C. Angus. 2021. "Alcohol deaths rise sharply in England and Wales " BMJ. doi: doi:10.1136/bmj.n607.

Howard, D. M., M. J. Adams, T. K. Clarke, J. D. Hafferty, J. Gibson, M. Shirali, J. R. I. Coleman, S. P. Hagenaars, J. Ward, E. M. Wigmore, C. Alloza, X. Shen, M. C. Barbu, E. Y. Xu, H. C. Whalley, R. E. Marioni, D. J. Porteous, G. Davies, I. J. Deary, G. Hemani, K. Berger, H. Teismann, R. Rawal, V. Arolt, B. T. Baune, U. 
Dannlowski, K. Domschke, C. Tian, D. A. Hinds, Team andMe Research, Consortium Major Depressive Disorder Working Group of the Psychiatric Genomics, M. Trzaskowski, E. M. Byrne, S. Ripke, D. J. Smith, P. F. Sullivan, N. R. Wray, G. Breen, C. M. Lewis, and A. M. McIntosh. 2019. "Genome-wide meta-analysis of depression identifies 102 independent variants and highlights the importance of the prefrontal brain regions." Nat Neurosci 22 (3):343-352. doi: 10.1038/s41593-0180326-7.

Jackson, S. E., J. Brown, L. Shahab, A. Steptoe, and D. Fancourt. 2020. "COVID-19, smoking and inequalities: a study of 53002 adults in the UK." Tob Control. doi: 10.1136/tobaccocontrol-2020-055933.

Jarbin, H., T. Ivarsson, M. Andersson, H. Bergman, and G. Skarphedinsson. 2020. "Screening efficiency of the Mood and Feelings Questionnaire (MFQ) and Short Mood and Feelings Questionnaire (SMFQ) in Swedish help seeking outpatients." PLoS One 15 (3):e0230623. doi: 10.1371/journal.pone.0230623.

Kelly, B.C., M. Pawson, and M. Vuolo. 2020. "Beliefs on COVID-19 among electronic cigarette users: Behavioral responses and implications for COVID prevention and Ecigarette interventions." Journal of Drug Issues 51 (2):284-300.

Kelly, T.M., J.E. Donovan, T. Chung, O.G. Bukstein, and J.R. Cornelius. 2009. "Brief screens for detecting alcohol use disorder among 18-20 year old young adults in emergency departments: Comparing AUDIT-C, CRAFFT, RAPS4-QF, FAST, RUFT-Cut, and DSM-IV 2-Item Scale." Addict Behav 34 (8):668-674.

Kroenke, K., R. L. Spitzer, J. B. Williams, P. O. Monahan, and B. Lowe. 2007. "Anxiety disorders in primary care: prevalence, impairment, comorbidity, and detection." Ann Intern Med 146 (5):317-25. doi: 10.7326/0003-4819-146-5-200703060-00004. 
Kwong, A. S. F., R. M. Pearson, M. J. Adams, K. Northstone, K. Tilling, D. Smith, C. Fawns-Ritchie, H. Bould, N. Warne, S. Zammit, D. J. Gunnell, P. A. Moran, N. Micali, A. Reichenberg, M. Hickman, D. Rai, S. Haworth, A. Campbell, D. Altschul, R. Flaig, A. M. McIntosh, D. A. Lawlor, D. Porteous, and N. J. Timpson. 2020. "Mental health before and during the COVID-19 pandemic in two longitudinal UK population cohorts." Br J Psychiatry:1-10. doi: 10.1192/bjp.2020.242.

Lamers, F., P. van Oppen, H. C. Comijs, J. H. Smit, P. Spinhoven, A. J. van Balkom, W. A. Nolen, F. G. Zitman, A. T. Beekman, and B. W. Penninx. 2011. "Comorbidity patterns of anxiety and depressive disorders in a large cohort study: the Netherlands Study of Depression and Anxiety (NESDA)." J Clin Psychiatry 72 (3):341-8. doi: 10.4088/JCP.10m06176blu.

Lanciano, T., G. Graziano, A. Curci, S. Costadura, and A. Monaco. 2020. "Risk perceptions and psychological effects during the Italian COVID-19 emergency." Front Psychol 11:580053. doi: 10.3389/fpsyg.2020.580053.

Lerner, J.S. , and D. Keltner. 2000. "Beyond valence: Toward a model of emotionspecific influences on judgement and choice." Cognition and Emotion 14 (4):473-493. doi: 10.1080/026999300402763.

Li, R., S. Pei, B. Chen, Y. Song, T. Zhang, W. Yang, and J. Shaman. 2020. "Substantial undocumented infection facilitates the rapid dissemination of novel coronavirus (SARS-CoV-2)." Science 368 (6490):489-493. doi: 10.1126/science.abb3221.

Li, S., and X. Hua. 2021. "Modifiable lifestyle factors and severe COVID-19 risk: a Mendelian randomisation study." BMC Med Genomics 14 (1):38. doi: 10.1186/s12920-021-00887-1. 
Li, X., and H. Lyu. 2020. "Epidemic risk perception, perceived stress, and mental health during COVID-19 pandemic: A moderated mediating model." Front Psychol 11:563741. doi: 10.3389/fpsyg.2020.563741.

Liu, M., H. Zhang, and H. Huang. 2020. "Media exposure to COVID-19 information, risk perception, social and geographical proximity, and self-rated anxiety in China." $B M C$ Public Health 20 (1):1649. doi: 10.1186/s12889-020-09761-8.

Long, N.N., and B.H. Khoi. 2020. "An empirical study about the intention to hoard food during COVID-19 pandemic." Eurasia Journal of Mathematics, Science and Technology Education 16 (7). doi: https://doi.org/10.29333/ejmste/8207.

Majmundar, A., J. P. Allem, T. B. Cruz, and J. B. Unger. 2020. "Public health concerns and unsubstantiated claims at the intersection of vaping and COVID-19." Nicotine Tob Res 22 (9):1667-1668. doi: 10.1093/ntr/ntaa064.

McCloskey, B., and D. L. Heymann. 2020. "SARS to novel coronavirus - old lessons and new lessons." Epidemiol Infect 148:e22. doi: 10.1017/S0950268820000254.

Mind. 2020. The mental health emergency: how has the coronavirus pandemic impacted our mental health? London: Mind.

Mueller, A. L., M. S. McNamara, and D. A. Sinclair. 2020. "Why does COVID-19 disproportionately affect older people?" Aging (Albany NY) 12 (10):9959-9981. doi: 10.18632/aging.103344.

Northstone, K., S. Howarth, D. Smith, C. Bowring, N. Wells, and N. J. Timpson. 2020. "The Avon Longitudinal Study of Parents and Children - A resource for COVID-19 research: Questionnaire data capture April-May 2020." Wellcome Open Res 5:127. doi: 10.12688/wellcomeopenres.16020.2.

Northstone, K., M. Lewcock, A. Groom, A. Boyd, J. Macleod, N. Timpson, and N. Wells. 2019. "The Avon Longitudinal Study of Parents and Children (ALSPAC): an update 
on the enrolled sample of index children in 2019." Wellcome Open Res 4:51. doi: 10.12688/wellcomeopenres.15132.1.

Northstone, K., D. Smith, C. Bowring, N. Wells, M. Crawford, S. Haworth, and N. J. Timpson. 2020. "The Avon Longitudinal Study of Parents and Children - A resource for COVID-19 research: Questionnaire data capture May-July 2020." Wellcome Open Res 5:210. doi: 10.12688/wellcomeopenres.16225.2.

Orte, C., L. Sanchez-Prieto, D. C. Dominguez, and A. Barrientos-Baez. 2020. "Evaluation of distress and risk perception associated with COVID-19 in vulnerable groups." Int J Environ Res Public Health 17 (24). doi: 10.3390/ijerph17249207.

Paek, H-J., and T. Hove. 2017. Risk Perceptions and Risk Characteristics. In Oxford Research Encyclopedia of Communication. USA: Oxford University Press.

Panno, A., G. A. Carbone, C. Massullo, B. Farina, and C. Imperatori. 2020. "COVID-19 related distress Is associated with alcohol problems, social media and food addiction symptoms: Insights from the Italian experience during the lockdown." Front Psychiatry 11:577135. doi: 10.3389/fpsyt.2020.577135.

Peltier, M. R., T. L. Verplaetse, Y. S. Mineur, I. L. Petrakis, K. P. Cosgrove, M. R. Picciotto, and S. A. McKee. 2019. "Sex differences in stress-related alcohol use." Neurobiol Stress 10:100149. doi: 10.1016/j.ynstr.2019.100149.

Phillips, N. 2021. "The coronavirus is here to stay - here's what that means." Nature 590 (7846):382-384. doi: 10.1038/d41586-021-00396-2.

Purves, K. L., J. R. I. Coleman, S. M. Meier, C. Rayner, K. A. S. Davis, R. Cheesman, M. Baekvad-Hansen, A. D. Borglum, S. Wan Cho, J. Jurgen Deckert, H. A. Gaspar, J. Bybjerg-Grauholm, J. M. Hettema, M. Hotopf, D. Hougaard, C. Hubel, C. Kan, A. M. McIntosh, O. Mors, P. Bo Mortensen, M. Nordentoft, T. Werge, K. K. Nicodemus, M. Mattheisen, G. Breen, and T. C. Eley. 2020. "A major role for common genetic 
variation in anxiety disorders." Mol Psychiatry 25 (12):3292-3303. doi: $10.1038 / \mathrm{s} 41380-019-0559-1$.

Rabner, J., N. D. Mian, D. A. Langer, J. S. Comer, and D. Pincus. 2017. "The relationship between worry and dimensions of anxiety symptoms in children and adolescents." Behav Cogn Psychother 45 (2):124-138. doi: 10.1017/S1352465816000448.

Richardson, T. G., S. Harrison, G. Hemani, and G. Davey Smith. 2019. "An atlas of polygenic risk score associations to highlight putative causal relationships across the human phenome." Elife 8. doi: 10.7554/eLife.43657.

Rodriguez-Besteiro, S., J. F. Tornero-Aguilera, J. Fernandez-Lucas, and V. J. ClementeSuarez. 2021. "Gender differences in the COVID-19 pandemic risk perception, psychology, and behaviors of Spanish university students." Int J Environ Res Public Health 18 (8). doi: 10.3390/ijerph18083908.

Rogers, R. D. 1975. "A Protection Motivation Theory of fear appeals and attitude change." The Journal of Psychology 91 (1):93-114. doi: doi:10.1080/00223980.1975.9915803.

Saengow, U., S. Assanangkornchai, and S. Casswell. 2021. "Alcohol: a probable risk factor of COVID-19 severity." Addiction 116 (1):204-205. doi: 10.1111/add.15194.

Sallie, S. N., V. Ritou, H. Bowden-Jones, and V. Voon. 2020. "Assessing international alcohol consumption patterns during isolation from the COVID-19 pandemic using an online survey: highlighting negative emotionality mechanisms." BMJ Open 10 (11):e044276. doi: 10.1136/bmjopen-2020-044276.

Savadori, L., and M. Lauriola. 2020. "Risk perception and protective behaviors during the rise of the COVID-19 outbreak in Italy." Front Psychol 11:577331. doi: 10.3389/fpsyg.2020.577331.

Schneider, C.R., S. Dryhurst, J. Kerr, A.L.J Freeman, G. Recchia, D. Spiegelhalter, and S. van der Linden. 2021. "COVID-19 risk perception: a longitudinal analysis of its 
predictors and associations with health protective behaviours in the United Kingdom." Journal of Risk Research. doi: https://doi.org/10.1080/13669877.2021.1890637.

Shepherd, J. M., B. Fogle, L. Garey, A. G. Viana, and M. J. Zvolensky. 2021. "Worry about COVID-19 in relation to cognitive-affective smoking processes among daily adult combustible cigarette smokers." Cogn Behav Ther:1-15. doi: $10.1080 / 16506073.2020 .1866657$.

Smith, L. E., A. L. Mottershaw, M. Egan, J. Waller, T. M. Marteau, and G. J. Rubin. 2020. "The impact of believing you have had COVID-19 on self-reported behaviour: Crosssectional survey." PLoS One 15 (11):e0240399. doi: 10.1371/journal.pone.0240399.

Spitzer, R. L., K. Kroenke, J. B. Williams, and B. Lowe. 2006. "A brief measure for assessing generalized anxiety disorder: the GAD-7." Arch Intern Med 166 (10):10927. doi: 10.1001/archinte.166.10.1092.

Sterne, J. A., and G. Davey Smith. 2001. "Sifting the evidence-what's wrong with significance tests?" $B M J 322$ (7280):226-31. doi: 10.1136/bmj.322.7280.226.

Tennant, R., L. Hiller, R. Fishwick, S. Platt, S. Joseph, S. Weich, J. Parkinson, J. Secker, and S. Stewart-Brown. 2007. "The Warwick-Edinburgh Mental Well-being Scale (WEMWBS): Development and UK validation." Health Qual Life Outcomes 5:63. doi: 10.1186/1477-7525-5-63.

Tzu-Hsuan Chen, D. 2020. "The psychosocial impact of the COVID-19 pandemic on changes in smoking behavior: Evidence from a nationwide survey in the UK." Tob Prev Cessat 6:59. doi: 10.18332/tpc/126976.

van Westen-Lagerweij, N. A., E. Meijer, E. G. Meeuwsen, N. H. Chavannes, M. C. Willemsen, and E. A. Croes. 2021. "Are smokers protected against SARS-CoV-2 infection (COVID-19)? The origins of the myth." NPJ Prim Care Respir Med 31 (1):10. doi: 10.1038/s41533-021-00223-1. 
Vardavas, C. I., and K. Nikitara. 2020. "COVID-19 and smoking: A systematic review of the evidence." Tob Induc Dis 18:20. doi: 10.18332/tid/119324.

Warwick Medical School. 2021. "Collect, score, analyse and interpret WEMWBS." https://warwick.ac.uk/fac/sci/med/research/platform/wemwbs/using/howto/.

White, C., and D. Ayoubkhani. 2020. Rates of deaths involving the coronavirus (COVID-19) by ethnic group, England and Wales. edited by Office for National Statistics.

Wise, T., T. D. Zbozinek, G. Michelini, C. C. Hagan, and D. Mobbs. 2020. "Changes in risk perception and self-reported protective behaviour during the first week of the COVID-19 pandemic in the United States." R Soc Open Sci 7 (9):200742. doi: 10.1098/rsos.200742.

World Health Organisation. 2021a. "Timeline: WHO's COVID-19 response." https://www.who.int/emergencies/diseases/novel-coronavirus-2019/interactivetimeline/\#!

World Health Organisation. 2021b. "WHO coronavirus (COVID-19) dashboard." https://covid19.who.int/.

Wright, L., A. Steptoe, and D. Fancourt. 2021. "Does thinking make it so? Differential associations between adversity worries and experiences and mental health during the COVID-19 pandemic." J Epidemiol Community Health. doi: 10.1136/jech-2020215598.

Yin, Q., A. Chen, X. Song, G. Deng, and W. Dong. 2021. "Risk perception and PTSD symptoms of medical staff combating against COVID-19: A PLS structural equation model." Front Psychiatry 12:607612. doi: 10.3389/fpsyt.2021.607612.

Yingst, J. M., N. M. Krebs, C. R. Bordner, A. L. Hobkirk, S. I. Allen, and J. Foulds. 2021. "Tobacco use changes and perceived health risks among current tobacco ssers during 
the COVID-19 pandemic." Int J Environ Res Public Health 18 (4). doi: 10.3390/ijerph18041795.

Zhong, Y., W. Liu, T. Y. Lee, H. Zhao, and J. Ji. 2021. "Risk perception, knowledge, information sources and emotional states among COVID-19 patients in Wuhan, China." Nurs Outlook 69 (1):13-21. doi: 10.1016/j.outlook.2020.08.005. 


\section{Table 1}

Cross-Sectional Associations between COVID-19 Risk Perceptions and Mental Health, Wellbeing, and Risk Behaviours (Whole Sample)

\begin{tabular}{|c|c|c|c|c|c|c|c|c|c|c|c|c|c|c|c|}
\hline \multirow[b]{3}{*}{ Outcome and Model } & \multicolumn{15}{|c|}{ COVID-19 Risk Perceptions (Exposures) } \\
\hline & \multicolumn{3}{|c|}{ Holistic } & \multicolumn{3}{|c|}{ Cognitive } & \multicolumn{3}{|c|}{ Affective } & \multicolumn{3}{|c|}{ Self } & \multicolumn{3}{|c|}{ Other } \\
\hline & $\begin{array}{c}\text { OR } \\
(95 \% \mathrm{CI}) \\
\end{array}$ & $\mathbf{P}$ & $\mathbf{N}$ & $\begin{array}{c}\text { OR } \\
(95 \% \mathrm{CI}) \\
\end{array}$ & $\mathbf{P}$ & $\mathbf{N}$ & $\begin{array}{c}\text { OR } \\
(95 \% \mathrm{CI}) \\
\end{array}$ & $\mathbf{P}$ & $\mathbf{N}$ & $\begin{array}{c}\text { OR } \\
(95 \% \mathrm{CI}) \\
\end{array}$ & $\mathbf{P}$ & $\mathbf{N}$ & $\begin{array}{c}\text { OR } \\
(95 \% \mathrm{CI}) \\
\end{array}$ & $\mathbf{P}$ & $\mathbf{N}$ \\
\hline \multicolumn{16}{|c|}{ Generalised Anxiety Disorder } \\
\hline Unadjusted & $\begin{array}{c}2.75 \\
(2.35,3.21)\end{array}$ & $<.001$ & 4982 & $\begin{array}{c}1.60 \\
(1.38,1.86)\end{array}$ & $<.001$ & 5065 & $\begin{array}{c}2.74 \\
(2.34 .3 .22)\end{array}$ & $<.001$ & 4994 & $\begin{array}{c}2.16 \\
(1.86,2.52)\end{array}$ & $<.001$ & 5038 & $\begin{array}{c}3.00 \\
(2.55,3.53)\end{array}$ & $<.001$ & 5011 \\
\hline Partially Adjusted & $\begin{array}{c}3.05 \\
(2.55,3.66)\end{array}$ & $<.001$ & 4244 & $\begin{array}{c}1.52 \\
(1.28,1.80)\end{array}$ & $<.001$ & 4314 & $\begin{array}{c}3.12 \\
(2.58,3.77)\end{array}$ & $<.001$ & 4255 & $\begin{array}{c}2.78 \\
(2.32,3.33)\end{array}$ & $<.001$ & 4289 & $\begin{array}{c}2.97 \\
(2.46,3.58)\end{array}$ & $<.001$ & 4270 \\
\hline Fully Adjusted & $\begin{array}{c}2.78 \\
(2.20,3.52)\end{array}$ & $<.001$ & 2780 & $\begin{array}{c}1.50 \\
(1.19,1.89) \\
\end{array}$ & .001 & 2820 & $\begin{array}{c}2.70 \\
(2.12,3.44) \\
\end{array}$ & $<.001$ & 2787 & $\begin{array}{c}2.63 \\
(2.08,3.32)\end{array}$ & $<.001$ & 2806 & $\begin{array}{c}2.71 \\
(2.12,3.45)\end{array}$ & $<.001$ & 2796 \\
\hline \multicolumn{16}{|l|}{ Depression } \\
\hline Unadjusted & $\begin{array}{c}1.81 \\
(1.52,2.16)\end{array}$ & $<.001$ & 4922 & $\begin{array}{c}1.42 \\
(1.20,1.69)\end{array}$ & $<.001$ & 5006 & $\begin{array}{c}1.81 \\
(1.51,2.16)\end{array}$ & $<.001$ & 4933 & $\begin{array}{c}1.45 \\
(1.22,1.72)\end{array}$ & $<.001$ & 4977 & $\begin{array}{c}2.03 \\
(1.70,2.43)\end{array}$ & $<.001$ & 4951 \\
\hline Partially Adjusted & $\begin{array}{c}1.90 \\
(1.55,2.34)\end{array}$ & $<.001$ & 4198 & $\begin{array}{c}1.23 \\
(1.00,1.50)\end{array}$ & .048 & 4268 & $\begin{array}{c}1.94 \\
(1.57,2.41)\end{array}$ & $<.001$ & 4208 & $\begin{array}{c}1.83 \\
(1.49,2.26)\end{array}$ & $<.001$ & 4242 & $\begin{array}{c}2.02 \\
(1.63,2.49)\end{array}$ & $<.001$ & 4224 \\
\hline Fully Adjusted & $\begin{array}{c}1.65 \\
(1.24,2.18) \\
\end{array}$ & $<.001$ & 2753 & $\begin{array}{c}1.12 \\
(0.85,1.47) \\
\end{array}$ & .430 & 2793 & $\begin{array}{c}1.77 \\
(1.33,2.36) \\
\end{array}$ & $<.001$ & 2760 & $\begin{array}{c}1.57 \\
(1.19,2.09) \\
\end{array}$ & .002 & 2778 & $\begin{array}{c}1.92 \\
(1.44,2.56) \\
\end{array}$ & $<.001$ & 2770 \\
\hline \multicolumn{16}{|l|}{ Low Wellbeing } \\
\hline Unadjusted & $\begin{array}{c}1.84 \\
(1.62,2.09)\end{array}$ & $<.001$ & 4942 & $\begin{array}{c}1.32 \\
(1.16,1.50)\end{array}$ & $<.001$ & 5025 & $\begin{array}{c}1.84 \\
(1.62,2.10)\end{array}$ & $<.001$ & 4954 & $\begin{array}{c}1.57 \\
(1.38,1.78)\end{array}$ & $<.001$ & 4997 & $\begin{array}{c}1.77 \\
(1.56,2.01)\end{array}$ & $<.001$ & 4972 \\
\hline Partially Adjusted & $\begin{array}{c}1.91 \\
(1.65,2.21)\end{array}$ & $<.001$ & 4213 & $\begin{array}{c}1.29 \\
(1.11,1.49)\end{array}$ & .001 & 4283 & $\begin{array}{c}1.94 \\
(1.67,2.26)\end{array}$ & $<.001$ & 4224 & $\begin{array}{c}1.82 \\
(1.57,2.12)\end{array}$ & $<.001$ & 4257 & $\begin{array}{c}1.74 \\
(1.50,2.01)\end{array}$ & $<.001$ & 4240 \\
\hline Fully Adjusted & $\begin{array}{c}1.76 \\
(1.45,2.13) \\
\end{array}$ & $<.001$ & 2766 & $\begin{array}{c}1.18 \\
(0.97,1.43)\end{array}$ & .090 & 2806 & $\begin{array}{c}1.83 \\
(1.50,2.22)\end{array}$ & $<.001$ & 2773 & $\begin{array}{c}1.79 \\
(1.48,2.17)\end{array}$ & $<.001$ & 2791 & $\begin{array}{c}1.56 \\
(1.29,1.89)\end{array}$ & $<.001$ & 2783 \\
\hline \multicolumn{16}{|l|}{ High-Risk Drinking } \\
\hline Unadjusted & $\begin{array}{c}0.81 \\
(0.72,0.91)\end{array}$ & $\begin{array}{c}<.001 \\
\end{array}$ & 5022 & $\begin{array}{c}1.14 \\
(1.01,1.27)\end{array}$ & .027 & 5107 & $\begin{array}{c}0.76 \\
(0.67,0.85)\end{array}$ & $<.001$ & 5034 & $\begin{array}{c}0.75 \\
(0.67,0.84)\end{array}$ & $<.001$ & 5077 & $\begin{array}{c}0.91 \\
(0.81,1.02)\end{array}$ & .095 & 5051 \\
\hline Partially Adjusted & $\begin{array}{c}0.88 \\
(0.78,1.01)\end{array}$ & .061 & 4287 & $\begin{array}{c}1.09 \\
(0.97,1.24)\end{array}$ & .154 & 4358 & $\begin{array}{c}0.84 \\
(0.74,0.96)\end{array}$ & .009 & 4297 & $\begin{array}{c}0.87 \\
(0.77,0.99)\end{array}$ & .039 & 4331 & $\begin{array}{c}0.95 \\
(0.84,1.08)\end{array}$ & .458 & 4313 \\
\hline Fully Adjusted & $\begin{array}{c}0.95 \\
(0.79,1.13) \\
\end{array}$ & .537 & 2809 & $\begin{array}{c}1.18 \\
(0.99,1.40) \\
\end{array}$ & .059 & 2849 & $\begin{array}{c}0.89 \\
(0.74,1.06) \\
\end{array}$ & .188 & 2816 & $\begin{array}{c}0.98 \\
(0.82,1.18) \\
\end{array}$ & .860 & 2834 & $\begin{array}{c}0.97 \\
(0.82,1.15) \\
\end{array}$ & .726 & 2826 \\
\hline \multicolumn{16}{|l|}{ Increased Alcohol Use } \\
\hline Unadjusted & $\begin{array}{c}1.31 \\
(1.16,1.48)\end{array}$ & $<.001$ & 4334 & $\begin{array}{c}1.11 \\
(0.98,1.25)\end{array}$ & .092 & 4405 & $\begin{array}{c}1.31 \\
(1.16,1.47)\end{array}$ & $\begin{array}{l}<.001 \\
\end{array}$ & 4343 & $\begin{array}{c}1.22 \\
(1.09,1.38)\end{array}$ & .001 & 4379 & $\begin{array}{c}1.22 \\
(1.09,1.38)\end{array}$ & .001 & 4357 \\
\hline Partially Adjusted & $\begin{array}{c}1.40 \\
(1.23,1.60)\end{array}$ & $<.001$ & 3698 & $\begin{array}{c}1.13 \\
(0.99,1.29)\end{array}$ & .069 & 3758 & $\begin{array}{c}1.39 \\
(1.22,1.59)\end{array}$ & $<.001$ & 3704 & $\begin{array}{c}1.31 \\
(1.15,1.50)\end{array}$ & $<.001$ & 3734 & $\begin{array}{c}1.28 \\
(1.12,1.46)\end{array}$ & $<.001$ & 3719 \\
\hline Fully Adjusted & $\begin{array}{c}1.46 \\
(1.24,1.72) \\
\end{array}$ & $<.001$ & 2541 & $\begin{array}{c}1.13 \\
(0.96,1.32) \\
\end{array}$ & .140 & 2578 & $\begin{array}{c}1.52 \\
(1.29,1.79) \\
\end{array}$ & $<.001$ & 2544 & $\begin{array}{c}1.39 \\
(1.18,1.64) \\
\end{array}$ & $<.001$ & 2561 & $\begin{array}{c}1.29 \\
(1.10,1.52) \\
\end{array}$ & .001 & 2556 \\
\hline \multicolumn{16}{|c|}{ Increased Smoking/E-Cigarette Use } \\
\hline Unadjusted & $\begin{array}{c}1.41 \\
(1.08,1.82)\end{array}$ & .010 & 941 & $\begin{array}{c}1.13 \\
(0.87,1.46)\end{array}$ & .369 & 963 & $\begin{array}{c}1.30 \\
(1.00,1.68)\end{array}$ & .050 & 942 & $\begin{array}{c}1.14 \\
(0.88,1.48)\end{array}$ & .307 & 957 & $\begin{array}{c}1.47 \\
(1.13,1.90)\end{array}$ & .004 & 946 \\
\hline Partially Adjusted & 1.45 & .019 & 726 & 1.21 & .225 & 741 & 1.26 & .146 & 726 & 1.24 & .188 & 736 & 1.45 & .017 & 730 \\
\hline
\end{tabular}

Preprint (Version 2): 15th November 2021. This paper has not been peer reviewed. 


\begin{tabular}{|c|c|c|c|c|c|c|c|c|c|c|c|c|c|c|c|}
\hline Fully Adjusted & $\begin{array}{c}(1.06,1.98) \\
1.14 \\
(0.72,1.80)\end{array}$ & .586 & 420 & $\begin{array}{c}(0.89,1.63) \\
0.97 \\
(0.63,1.49) \\
\end{array}$ & .888 & 426 & $\begin{array}{c}(0.92,1.73) \\
0.98 \\
(0.63,1.54) \\
\end{array}$ & .942 & 420 & $\begin{array}{c}(0.90,1.69) \\
1.00 \\
(0.64,1.57) \\
\end{array}$ & .989 & 422 & $\begin{array}{c}(1.07,1.97) \\
1.31 \\
(0.85,2.03) \\
\end{array}$ & .222 & 423 \\
\hline \multicolumn{16}{|c|}{ Self-Isolating Given Suspected COVID-19 Infection } \\
\hline Unadjusted & $\begin{array}{c}1.40 \\
(1.04,1.90)\end{array}$ & .028 & 758 & $\begin{array}{c}2.24 \\
(1.65,3.05)\end{array}$ & $<.001$ & 777 & $\begin{array}{c}1.09 \\
(0.80,1.47)\end{array}$ & .589 & 761 & $\begin{array}{c}0.83 \\
(0.61,1.12)\end{array}$ & .218 & 765 & $\begin{array}{c}1.35 \\
(1.00,1.81)\end{array}$ & .047 & 769 \\
\hline Partially Adjusted & $\begin{array}{c}1.60 \\
(1.14,2.26)\end{array}$ & .007 & 638 & $\begin{array}{c}2.40 \\
(1.70,3.37)\end{array}$ & $<.001$ & 655 & $\begin{array}{c}1.27 \\
(0.90,1.78)\end{array}$ & .177 & 640 & $\begin{array}{c}0.92 \\
(0.65,1.30)\end{array}$ & .634 & 643 & $\begin{array}{c}1.40 \\
(1.01,1.95)\end{array}$ & .044 & 649 \\
\hline Fully Adjusted & $\begin{array}{c}1.74 \\
(1.13,2.68) \\
\end{array}$ & .012 & 413 & $\begin{array}{c}2.27 \\
(1.48,3.48) \\
\end{array}$ & $<.001$ & 422 & $\begin{array}{c}1.30 \\
(0.85,2.01) \\
\end{array}$ & .231 & 415 & $\begin{array}{c}0.98 \\
(0.63,1.54)\end{array}$ & .943 & 416 & $\begin{array}{c}1.42 \\
(0.94,2.16) \\
\end{array}$ & .096 & 421 \\
\hline \multicolumn{16}{|c|}{ Face-To-Face Contact Outside Household } \\
\hline Unadjusted & $\begin{array}{c}0.86 \\
(0.77,0.97)\end{array}$ & .011 & 5029 & $\begin{array}{c}0.86 \\
(0.77,0.97)\end{array}$ & .010 & 5115 & $\begin{array}{c}0.86 \\
(0.77,0.97)\end{array}$ & .012 & 5042 & $\begin{array}{c}1.00 \\
(0.90,1.13)\end{array}$ & .946 & 5085 & $\begin{array}{c}0.86 \\
(0.77,0.96)\end{array}$ & .010 & 5059 \\
\hline Partially Adjusted & $\begin{array}{c}0.77 \\
(0.67,0.88)\end{array}$ & $<.001$ & 4293 & $\begin{array}{c}0.91 \\
(0.80,1.04)\end{array}$ & .160 & 4365 & $\begin{array}{c}0.74 \\
(0.65,0.85)\end{array}$ & $<.001$ & 4304 & $\begin{array}{c}0.83 \\
(0.72,0.94)\end{array}$ & .005 & 4338 & $\begin{array}{c}0.83 \\
(0.73,0.95)\end{array}$ & .006 & 4320 \\
\hline Fully Adjusted & $\begin{array}{c}0.83 \\
(0.70,0.98) \\
\end{array}$ & .027 & 2816 & $\begin{array}{c}0.91 \\
(0.77,1.08) \\
\end{array}$ & .280 & 2857 & $\begin{array}{c}0.78 \\
(0.66,0.92) \\
\end{array}$ & .004 & 2823 & $\begin{array}{c}0.82 \\
(0.69,0.97) \\
\end{array}$ & .019 & 2842 & $\begin{array}{c}0.88 \\
(0.75,1.05) \\
\end{array}$ & .149 & 2833 \\
\hline \multicolumn{16}{|c|}{ Physical Contact Outside Household } \\
\hline Unadjusted & $\begin{array}{c}0.84 \\
(0.74,0.97)\end{array}$ & .016 & 4733 & $\begin{array}{c}0.79 \\
(0.69,0.91)\end{array}$ & .001 & 4812 & $\begin{array}{c}0.84 \\
(0.74,0.96)\end{array}$ & .013 & 4744 & $\begin{array}{c}0.84 \\
(0.73,0.96)\end{array}$ & .011 & 4785 & $\begin{array}{c}0.82 \\
(0.71,0.94)\end{array}$ & .004 & 4761 \\
\hline Partially Adjusted & $\begin{array}{c}0.85 \\
(0.73,0.98)\end{array}$ & .030 & 4046 & $\begin{array}{c}0.82 \\
(0.71,0.95)\end{array}$ & .008 & 4112 & $\begin{array}{c}0.83 \\
(0.72,0.97)\end{array}$ & .017 & 4056 & $\begin{array}{c}0.81 \\
(0.70,0.94)\end{array}$ & .007 & 4087 & $\begin{array}{c}0.83 \\
(0.71,0.96)\end{array}$ & .012 & 4072 \\
\hline Fully Adjusted & $\begin{array}{c}0.83 \\
(0.68,1.00) \\
\end{array}$ & .049 & 2662 & $\begin{array}{c}0.78 \\
(0.65,0.94) \\
\end{array}$ & .008 & 2700 & $\begin{array}{c}0.79 \\
(0.65,0.95) \\
\end{array}$ & .013 & 2668 & $\begin{array}{c}0.71 \\
(0.60,0.86) \\
\end{array}$ & $<.001$ & 2685 & $\begin{array}{c}0.84 \\
(0.69,1.01) \\
\end{array}$ & .057 & 2678 \\
\hline
\end{tabular}

Note. Logistic regressions. OR = odds ratio. CI = confidence interval. Partially adjusted = adjusted for sociodemographic variables (age, gender, education, and keyworker status). Fully adjusted = additionally adjusted for prior mental health and risk behaviour variables (anxiety, depression, high-risk drinking, smoking, and suspected COVID-19 infection). All variables in the models are binary. All risk perception variables were dichotomised at the median. 


\section{Table 2}

Longitudinal Associations between Pre-pandemic Mental Health, Wellbeing, and Risk Behaviours and COVID-19 Risk Perceptions (Whole Sample)

\begin{tabular}{|c|c|c|c|c|c|c|c|c|c|c|c|c|c|c|c|}
\hline \multirow[b]{3}{*}{ Exposure and Model } & \multicolumn{15}{|c|}{ COVID-19 Risk Perceptions (Outcomes) } \\
\hline & \multicolumn{3}{|c|}{ Holistic } & \multicolumn{3}{|c|}{ Cognitive } & \multicolumn{3}{|c|}{ Affective } & \multicolumn{3}{|c|}{ Self } & \multicolumn{3}{|c|}{ Other } \\
\hline & $\begin{array}{c}\text { OR } \\
(95 \% \mathrm{CI})\end{array}$ & $\mathbf{P}$ & $\mathbf{N}$ & $\begin{array}{c}\text { OR } \\
(95 \% \mathrm{CI})\end{array}$ & $\mathbf{P}$ & $\mathbf{N}$ & $\begin{array}{c}\text { OR } \\
(95 \% \mathrm{CI})\end{array}$ & $\mathbf{P}$ & $\mathbf{N}$ & $\begin{array}{c}\text { OR } \\
(95 \% \mathrm{CI})\end{array}$ & $\mathbf{P}$ & $\mathbf{N}$ & $\begin{array}{c}\text { OR } \\
(95 \% \mathrm{CI})\end{array}$ & $\mathbf{P}$ & $\mathbf{N}$ \\
\hline \multicolumn{16}{|l|}{ Pre-pandemic Anxiety } \\
\hline Unadjusted & $\begin{array}{c}1.52 \\
(1.30,1.78)\end{array}$ & $<.001$ & 4165 & $\begin{array}{c}1.09 \\
(0.93,1.28)\end{array}$ & .276 & 4235 & $\begin{array}{c}1.65 \\
(1.41,1.93)\end{array}$ & $<.001$ & 4175 & $\begin{array}{c}1.52 \\
(1.30,1.78)\end{array}$ & $<.001$ & 4207 & $\begin{array}{c}1.41 \\
(1.20,1.65)\end{array}$ & $<.001$ & 4192 \\
\hline Partially Adjusted & $\begin{array}{c}1.47 \\
(1.23,1.75)\end{array}$ & $<.001$ & 3673 & $\begin{array}{c}1.24 \\
(1.04,1.47)\end{array}$ & .014 & 3733 & $\begin{array}{c}1.54 \\
(1.29,1.84)\end{array}$ & $<.001$ & 3682 & $\begin{array}{c}1.25 \\
(1.05,1.49)\end{array}$ & .012 & 3709 & $\begin{array}{c}1.50 \\
(1.27,1.79)\end{array}$ & $<.001$ & 3697 \\
\hline Fully Adjusted & $\begin{array}{c}1.64 \\
(1.29,2.09)\end{array}$ & $<.001$ & 2533 & $\begin{array}{c}1.34 \\
(1.06,1.71)\end{array}$ & .016 & 2570 & $\begin{array}{c}1.74 \\
(1.37,2.22)\end{array}$ & $<.001$ & 2539 & $\begin{array}{c}1.44 \\
(1.13,1.84) \\
\end{array}$ & .003 & 2557 & $\begin{array}{c}1.75 \\
(1.37,2.22) \\
\end{array}$ & $<.001$ & 2547 \\
\hline \multicolumn{16}{|l|}{ Pre-pandemic Depression } \\
\hline Unadjusted & $\begin{array}{c}1.30 \\
(1.11,1.53)\end{array}$ & .002 & 4174 & $\begin{array}{c}1.02 \\
(0.87,1.20)\end{array}$ & .815 & 4243 & $\begin{array}{c}1.34 \\
(1.14,1.58)\end{array}$ & $<.001$ & 4184 & $\begin{array}{c}1.21 \\
(1.03,1.42)\end{array}$ & .022 & 4216 & $\begin{array}{c}1.22 \\
(1.04,1.44)\end{array}$ & .016 & 4201 \\
\hline Partially Adjusted & $\begin{array}{c}1.17 \\
(0.98,1.41)\end{array}$ & .084 & 3680 & $\begin{array}{c}1.10 \\
(0.92,1.31)\end{array}$ & .294 & 3740 & $\begin{array}{c}1.23 \\
(1.02,1.47)\end{array}$ & .026 & 3689 & $\begin{array}{c}1.02 \\
(0.85,1.23)\end{array}$ & .808 & 3716 & $\begin{array}{c}1.18 \\
(0.99,1.41)\end{array}$ & .069 & 3705 \\
\hline Fully Adjusted & $\begin{array}{c}0.94 \\
(0.73,1.22) \\
\end{array}$ & .648 & 2533 & $\begin{array}{c}0.98 \\
(0.77,1.26) \\
\end{array}$ & .903 & 2570 & $\begin{array}{c}0.95 \\
(0.74,1.23)\end{array}$ & .716 & 2539 & $\begin{array}{c}0.86 \\
(0.66,1.12) \\
\end{array}$ & .263 & 2557 & $\begin{array}{c}0.88 \\
(0.68,1.14) \\
\end{array}$ & .341 & 2547 \\
\hline \multicolumn{16}{|c|}{ Pre-pandemic Low Wellbeing } \\
\hline Unadjusted & $\begin{array}{c}1.51 \\
(1.30,1.75)\end{array}$ & $<.001$ & 4056 & $\begin{array}{c}1.19 \\
(1.03,1.38)\end{array}$ & .019 & 4125 & $\begin{array}{c}1.58 \\
(1.36,1.84)\end{array}$ & $<.001$ & 4067 & $\begin{array}{c}1.55 \\
(1.34,1.80)\end{array}$ & $<.001$ & 4102 & $\begin{array}{c}1.45 \\
(1.25,1.69)\end{array}$ & $\begin{array}{c}<.001 \\
\end{array}$ & 4080 \\
\hline Partially Adjusted & $\begin{array}{c}1.47 \\
(1.25,1.74)\end{array}$ & $<.001$ & 3597 & $\begin{array}{c}1.24 \\
(1.06,1.45)\end{array}$ & .008 & 3657 & $\begin{array}{c}1.52 \\
(1.29,1.80)\end{array}$ & $<.001$ & 3606 & $\begin{array}{c}1.40 \\
(1.19,1.65)\end{array}$ & $<.001$ & 3636 & $\begin{array}{c}1.46 \\
(1.24,1.72)\end{array}$ & $<.001$ & 3619 \\
\hline Fully Adjusted & $\begin{array}{c}1.41 \\
(1.15,1.74) \\
\end{array}$ & .001 & 2465 & $\begin{array}{c}1.19 \\
(0.97,1.46) \\
\end{array}$ & .101 & 2502 & $\begin{array}{c}1.52 \\
(1.24,1.87) \\
\end{array}$ & $<.001$ & 2471 & $\begin{array}{c}1.53 \\
(1.24,1.89) \\
\end{array}$ & $<.001$ & 2489 & $\begin{array}{c}1.34 \\
(1.09,1.65) \\
\end{array}$ & .005 & 2479 \\
\hline \multicolumn{16}{|c|}{ Pre-pandemic High-Risk Drinking } \\
\hline Unadjusted & $\begin{array}{c}0.79 \\
(0.69,0.90)\end{array}$ & $<.001$ & 3738 & $\begin{array}{c}1.06 \\
(0.93,1.20)\end{array}$ & .388 & 3796 & $\begin{array}{c}0.73 \\
(0.64,0.84)\end{array}$ & $<.001$ & 3748 & $\begin{array}{c}0.63 \\
(0.56,0.72)\end{array}$ & $<.001$ & 3777 & $\begin{array}{c}0.93 \\
(0.82,1.06)\end{array}$ & .290 & 3760 \\
\hline Partially Adjusted & $\begin{array}{c}0.90 \\
(0.76,1.04)\end{array}$ & .144 & 3332 & $\begin{array}{c}0.94 \\
(0.81,1.08)\end{array}$ & .371 & 3382 & $\begin{array}{c}0.88 \\
(0.76,1.02)\end{array}$ & .079 & 3341 & $\begin{array}{c}0.80 \\
(0.69,0.93)\end{array}$ & .003 & 3365 & $\begin{array}{c}0.98 \\
(0.85,1.13)\end{array}$ & .757 & 3352 \\
\hline Fully Adjusted & $\begin{array}{c}0.89 \\
(0.75,1.06) \\
\end{array}$ & .192 & 2533 & $\begin{array}{c}0.97 \\
(0.82,1.14) \\
\end{array}$ & .702 & 2570 & $\begin{array}{c}0.89 \\
(0.74,1.05)\end{array}$ & .169 & 2539 & $\begin{array}{c}0.78 \\
(0.65,0.92) \\
\end{array}$ & .004 & 2557 & $\begin{array}{c}1.02 \\
(0.86,1.21) \\
\end{array}$ & .807 & 2547 \\
\hline \multicolumn{16}{|l|}{ Pre-pandemic Smoking } \\
\hline Unadjusted & $\begin{array}{c}1.05 \\
(0.89,1.24)\end{array}$ & .573 & 4135 & $\begin{array}{c}1.06 \\
(0.90,1.26)\end{array}$ & .485 & 4198 & $\begin{array}{c}1.04 \\
(0.87,1.23)\end{array}$ & .687 & 4145 & $\begin{array}{c}0.93 \\
(0.78,1.10)\end{array}$ & .384 & 4175 & $\begin{array}{c}1.28 \\
(1.08,1.52)\end{array}$ & .005 & 4159 \\
\hline Partially Adjusted & $\begin{array}{c}1.11 \\
(0.91,1.35)\end{array}$ & .308 & 3670 & $\begin{array}{c}1.01 \\
(0.83,1.22)\end{array}$ & .957 & 3726 & $\begin{array}{c}1.10 \\
(0.91,1.34)\end{array}$ & .332 & 3679 & $\begin{array}{c}1.14 \\
(0.94,1.38)\end{array}$ & .186 & 3705 & $\begin{array}{c}1.22 \\
(1.00,1.48)\end{array}$ & .048 & 3692 \\
\hline Fully Adjusted & $\begin{array}{c}0.96 \\
(0.74,1.24)\end{array}$ & .755 & 2533 & $\begin{array}{c}1.01 \\
(0.78,1.29)\end{array}$ & .966 & 2570 & $\begin{array}{c}0.94 \\
(0.73,1.22)\end{array}$ & .667 & 2539 & $\begin{array}{c}1.08 \\
(0.84,1.40)\end{array}$ & .529 & 2557 & $\begin{array}{c}1.12 \\
(0.86,1.45)\end{array}$ & .394 & 2547 \\
\hline
\end{tabular}

Note. Logistic regressions. OR = odds ratio. CI = confidence interval. Partially adjusted = adjusted for sociodemographic variables (age, gender, education, and keyworker status). Fully adjusted = additionally adjusted for prior mental health and risk behaviour variables (pre-pandemic anxiety, depression, high-risk drinking, smoking, and early

Preprint (Version 2): 15th November 2021. This paper has not been peer reviewed. 
pandemic suspected COVID-19 infection). The same sociodemographic variables are included in all partially adjusted models. However, the variables in the fully adjusted models differ based on the exposure in each model (e.g., pre-pandemic anxiety is removed as a confounder when pre-pandemic anxiety is the exposure). All variables in the models are binary. All risk perception variables were dichotomised at the median.

Preprint (Version 2): 15th November 2021. This paper has not been peer reviewed. 


\section{Table 3}

Longitudinal Associations between Early Pandemic Risk Behaviours and COVID-19 Risk Perceptions (Whole Sample)

\begin{tabular}{|c|c|c|c|c|c|c|c|c|c|c|c|c|c|c|c|}
\hline \multirow[b]{3}{*}{ Exposure and Model } & \multicolumn{15}{|c|}{ COVID-19 Risk Perceptions (Outcomes) } \\
\hline & \multicolumn{3}{|c|}{ Holistic } & \multicolumn{3}{|c|}{ Cognitive } & \multicolumn{3}{|c|}{ Affective } & \multicolumn{3}{|c|}{ Self } & \multicolumn{3}{|c|}{ Other } \\
\hline & $\begin{array}{c}\text { OR } \\
(95 \% \mathrm{CI})\end{array}$ & $\mathbf{P}$ & $\mathbf{N}$ & $\begin{array}{c}\text { OR } \\
(95 \% \mathrm{CI})\end{array}$ & $\mathbf{P}$ & $\mathbf{N}$ & $\begin{array}{c}\text { OR } \\
(95 \% \mathrm{CI})\end{array}$ & $\mathbf{P}$ & $\mathbf{N}$ & $\begin{array}{c}\text { OR } \\
(95 \% \mathrm{CI})\end{array}$ & $\mathbf{P}$ & $\mathbf{N}$ & $\begin{array}{c}\text { OR } \\
(95 \% \mathrm{CI})\end{array}$ & $\mathbf{P}$ & $\mathbf{N}$ \\
\hline \multicolumn{16}{|c|}{ Early Pandemic Self-Isolating Given Suspected COVID-19 Infection } \\
\hline Unadjusted & $\begin{array}{c}1.45 \\
(0.88,2.37)\end{array}$ & .142 & 394 & $\begin{array}{c}1.27 \\
(0.79,2.05)\end{array}$ & .323 & 410 & $\begin{array}{c}1.57 \\
(0.96,2.57)\end{array}$ & .073 & 395 & $\begin{array}{c}1.29 \\
(0.79,2.11)\end{array}$ & .304 & 400 & $\begin{array}{c}1.33 \\
(0.82,2.15)\end{array}$ & .245 & 401 \\
\hline Partially Adjusted & $\begin{array}{c}1.11 \\
(0.63,1.94)\end{array}$ & .724 & 352 & $\begin{array}{c}1.41 \\
(0.82,2.44)\end{array}$ & .212 & 366 & $\begin{array}{c}1.20 \\
(0.68,2.10)\end{array}$ & .534 & 353 & $\begin{array}{c}0.92 \\
(0.52,1.62)\end{array}$ & .766 & 357 & $\begin{array}{c}1.05 \\
(0.60,1.82)\end{array}$ & .868 & 359 \\
\hline Fully Adjusted & $\begin{array}{c}1.26 \\
(0.64,2.48)\end{array}$ & .500 & 245 & $\begin{array}{c}1.53 \\
(0.81,2.87)\end{array}$ & .188 & 253 & $\begin{array}{c}1.44 \\
(0.73,2.86)\end{array}$ & .295 & 233 & $\begin{array}{c}0.83 \\
(0.42,1.64)\end{array}$ & .587 & 248 & $\begin{array}{c}1.31 \\
(0.69,2.47)\end{array}$ & .413 & 251 \\
\hline \multicolumn{16}{|c|}{ Early Pandemic Face-To-Face Contact Outside Household } \\
\hline Unadjusted & $\begin{array}{c}0.95 \\
(0.84,1.08)\end{array}$ & .430 & 4056 & $\begin{array}{c}0.80 \\
(0.71,0.91)\end{array}$ & .001 & 4123 & $\begin{array}{c}0.97 \\
(0.86,1.10)\end{array}$ & .629 & 4067 & $\begin{array}{c}1.01 \\
(0.89,1.14)\end{array}$ & .890 & 4097 & $\begin{array}{c}0.91 \\
(0.80,1.03)\end{array}$ & .133 & 4081 \\
\hline Partially Adjusted & $\begin{array}{c}0.89 \\
(0.77,1.02)\end{array}$ & .096 & 3545 & $\begin{array}{c}0.83 \\
(0.72,0.95)\end{array}$ & .008 & 3604 & $\begin{array}{c}0.92 \\
(0.80,1.06)\end{array}$ & .270 & 3553 & $\begin{array}{c}0.90 \\
(0.78,1.04)\end{array}$ & .151 & 3581 & $\begin{array}{c}0.93 \\
(0.81,1.07)\end{array}$ & .289 & 3567 \\
\hline Fully Adjusted & $\begin{array}{c}0.93 \\
(0.78,1.11) \\
\end{array}$ & .434 & 2411 & $\begin{array}{c}0.88 \\
(0.75,1.05) \\
\end{array}$ & .155 & 2446 & $\begin{array}{c}0.98 \\
(0.82,1.16) \\
\end{array}$ & .805 & 2415 & $\begin{array}{c}0.92 \\
(0.77,1.10) \\
\end{array}$ & .355 & 2432 & $\begin{array}{c}1.05 \\
(0.88,1.24) \\
\end{array}$ & .609 & 2425 \\
\hline \multicolumn{16}{|c|}{ Early Pandemic Physical Contact Outside Household } \\
\hline Unadjusted & $\begin{array}{c}0.86 \\
(0.72,1.03)\end{array}$ & .103 & 3619 & $\begin{array}{c}0.82 \\
(0.68,0.98)\end{array}$ & .026 & 3674 & $\begin{array}{c}0.93 \\
(0.78,1.11)\end{array}$ & .411 & 3628 & $\begin{array}{c}0.93 \\
(0.78,1.11)\end{array}$ & .439 & 3653 & $\begin{array}{c}0.89 \\
(0.75,1.07)\end{array}$ & .220 & 3641 \\
\hline Partially Adjusted & $\begin{array}{c}0.89 \\
(0.73,1.08)\end{array}$ & .243 & 3166 & $\begin{array}{c}0.81 \\
(0.66,0.98)\end{array}$ & .030 & 3213 & $\begin{array}{c}0.97 \\
(0.80,1.18)\end{array}$ & .775 & 3174 & $\begin{array}{c}0.98 \\
(0.81,1.19)\end{array}$ & .835 & 3195 & $\begin{array}{c}0.92 \\
(0.76,1.12)\end{array}$ & .401 & 3185 \\
\hline Fully Adjusted & $\begin{array}{c}0.93 \\
(0.73,1.19)\end{array}$ & .563 & 2159 & $\begin{array}{c}0.91 \\
(0.71,1.15)\end{array}$ & .418 & 2189 & $\begin{array}{c}0.94 \\
(0.74,1.19)\end{array}$ & .596 & 2163 & $\begin{array}{c}1.01 \\
(0.79,1.28)\end{array}$ & .965 & 2177 & $\begin{array}{c}1.08 \\
(0.85,1.37)\end{array}$ & .539 & 2172 \\
\hline
\end{tabular}

Note. Logistic regressions. OR = odds ratio. CI = confidence interval. Partially adjusted = adjusted for sociodemographic variables (age, gender, education, and keyworker status). Fully adjusted = additionally adjusted for prior mental health and risk behaviour variables (pre-pandemic anxiety, depression, high-risk drinking, smoking, and early pandemic suspected COVID-19 infection). All variables in the models are binary. All risk perception variables were dichotomised at the median.

Preprint (Version 2): 15th November 2021. This paper has not been peer reviewed. 


\section{Table 4}

Prospective Longitudinal Associations between Mental Health and Wellbeing Polygenic Risk Scores and COVID-19 Risk Perceptions

\begin{tabular}{|c|c|c|c|c|c|c|c|c|c|c|c|c|c|c|c|}
\hline \multirow[b]{3}{*}{ Exposure and Model } & \multicolumn{15}{|c|}{ COVID-19 Risk Perceptions (Outcomes) } \\
\hline & \multicolumn{3}{|c|}{ Holistic } & \multicolumn{3}{|c|}{ Cognitive } & \multicolumn{3}{|c|}{ Affective } & \multicolumn{3}{|c|}{ Self } & \multicolumn{3}{|c|}{ Other } \\
\hline & $\begin{array}{c}b \\
(95 \% \mathrm{CI})\end{array}$ & $\mathbf{P}$ & $\mathbf{N}$ & $\begin{array}{c}b \\
(95 \% \mathrm{CI})\end{array}$ & $\mathbf{P}$ & $\mathbf{N}$ & $\begin{array}{c}b \\
(95 \% \mathrm{CI})\end{array}$ & $\mathbf{P}$ & $\mathbf{N}$ & $\begin{array}{c}b \\
(95 \% \mathrm{CI})\end{array}$ & $\mathbf{P}$ & $\mathbf{N}$ & $\begin{array}{c}b \\
(95 \% \mathrm{CI})\end{array}$ & $\mathbf{P}$ & $\mathbf{N}$ \\
\hline \multicolumn{16}{|l|}{ Whole Sample } \\
\hline \multicolumn{16}{|l|}{ Anxiety } \\
\hline Unadjusted & $\begin{array}{c}0.12 \\
(-0.07,0.32)\end{array}$ & .206 & 3615 & $\begin{array}{c}0.03 \\
(-0.03,0.09)\end{array}$ & .407 & 3672 & $\begin{array}{c}0.09 \\
(-0.08,0.25)\end{array}$ & .308 & 3623 & $\begin{array}{c}0.04 \\
(-0.06,0.13)\end{array}$ & .430 & 3652 & $\begin{array}{c}0.08 \\
(-0.03,0.20)\end{array}$ & .166 & 3633 \\
\hline Fully Adjusted & $\begin{array}{c}0.12 \\
(-0.08,0.31)\end{array}$ & .236 & 3615 & $\begin{array}{c}0.02 \\
(-0.04,0.08)\end{array}$ & .465 & 3672 & $\begin{array}{c}0.08 \\
(-0.08,0.25)\end{array}$ & .331 & 3623 & $\begin{array}{c}0.03 \\
(-0.06,0.13)\end{array}$ & .471 & 3652 & $\begin{array}{c}0.08 \\
(-0.04,0.20)\end{array}$ & .193 & 3633 \\
\hline \multicolumn{16}{|l|}{ Depression } \\
\hline Unadjusted & $\begin{array}{c}0.22 \\
(0.04,0.41)\end{array}$ & .018 & 3615 & $\begin{array}{c}0.02 \\
(-0.04,0.08)\end{array}$ & .578 & 3672 & $\begin{array}{c}0.20 \\
(0.04,0.36)\end{array}$ & .015 & 3623 & $\begin{array}{c}0.08 \\
(-0.01,0.17)\end{array}$ & .077 & 3652 & $\begin{array}{c}0.14 \\
(0.03,0.26)\end{array}$ & .014 & 3633 \\
\hline Fully Adjusted & $\begin{array}{c}0.21 \\
(0.02,0.40)\end{array}$ & .029 & 3615 & $\begin{array}{c}0.01 \\
(-0.05,0.07)\end{array}$ & .663 & 3672 & $\begin{array}{c}0.19 \\
(0.03,0.35)\end{array}$ & .023 & 3623 & $\begin{array}{c}0.06 \\
(-0.03,0.15) \\
\end{array}$ & .171 & 3652 & $\begin{array}{c}0.15 \\
(0.03,0.26)\end{array}$ & .013 & 3633 \\
\hline \multicolumn{16}{|l|}{ Wellbeing } \\
\hline Unadjusted & $\begin{array}{c}-0.29 \\
(-0.49,-0.10)\end{array}$ & .003 & 3615 & $\begin{array}{c}-0.02 \\
(-0.08,0.04)\end{array}$ & .501 & 3672 & $\begin{array}{c}-0.27 \\
(-0.44,-0.10)\end{array}$ & .001 & 3623 & $\begin{array}{c}-0.12 \\
(-0.21,-0.03)\end{array}$ & .007 & 3652 & $\begin{array}{c}-0.17 \\
(-0.29,-0.05)\end{array}$ & .006 & 3633 \\
\hline Fully Adjusted & $\begin{array}{c}-0.29 \\
(-0.48,-0.09)\end{array}$ & .004 & 3615 & $\begin{array}{c}-0.01 \\
(-0.08,0.05)\end{array}$ & .630 & 3672 & $\begin{array}{c}-0.27 \\
(-0.44,-0.10)\end{array}$ & .002 & 3623 & $\begin{array}{c}-0.11 \\
(-0.21,-0.02)\end{array}$ & .013 & 3652 & $\begin{array}{c}-0.17 \\
(-0.29,-0.05)\end{array}$ & .006 & 3633 \\
\hline \multicolumn{16}{|l|}{ Mother Sample } \\
\hline \multicolumn{16}{|l|}{ Anxiety } \\
\hline Unadjusted & $\begin{array}{c}0.11 \\
(-0.16,0.38)\end{array}$ & .426 & 1792 & $\begin{array}{c}-0.01 \\
(-0.09,0.07)\end{array}$ & .838 & 1824 & $\begin{array}{c}0.12 \\
(-0.12,0.35)\end{array}$ & .334 & 1796 & $\begin{array}{c}0.05 \\
(-0.07,0.18)\end{array}$ & .400 & 1806 & $\begin{array}{c}0.06 \\
(-0.11,0.22)\end{array}$ & .513 & 1807 \\
\hline Fully Adjusted & $\begin{array}{c}0.11 \\
(-0.17,0.38) \\
\end{array}$ & .444 & 1792 & $\begin{array}{c}-0.01 \\
(-0.09,0.07) \\
\end{array}$ & .810 & 1824 & $\begin{array}{c}0.12 \\
(-0.12,0.35) \\
\end{array}$ & .338 & 1796 & $\begin{array}{c}0.05 \\
(-0.08,0.18) \\
\end{array}$ & .444 & 1806 & $\begin{array}{c}0.06 \\
(-0.11,0.22) \\
\end{array}$ & .507 & 1807 \\
\hline \multicolumn{16}{|l|}{ Depression } \\
\hline Unadjusted & $\begin{array}{c}0.26 \\
(-0.01,0.53)\end{array}$ & .057 & 1792 & $\begin{array}{c}0.04 \\
(-0.04,0.12)\end{array}$ & .366 & 1824 & $\begin{array}{c}0.23 \\
(-0.00,0.46)\end{array}$ & .054 & 1796 & $\begin{array}{c}0.10 \\
(-0.03,0.22)\end{array}$ & .134 & 1806 & $\begin{array}{c}0.17 \\
(0.01,0.34)\end{array}$ & .037 & 1807 \\
\hline Fully Adjusted & $\begin{array}{c}0.26 \\
(-0.02,0.53) \\
\end{array}$ & .067 & 1792 & $\begin{array}{c}0.03 \\
(-0.05,0.11) \\
\end{array}$ & .495 & 1824 & $\begin{array}{c}0.24 \\
(-0.00,0.47) \\
\end{array}$ & .052 & 1796 & $\begin{array}{c}0.08 \\
(-0.05,0.21) \\
\end{array}$ & .209 & 1806 & $\begin{array}{c}0.19 \\
(0.02,0.36) \\
\end{array}$ & .027 & 1807 \\
\hline \multicolumn{16}{|l|}{ Wellbeing } \\
\hline Unadjusted & $\begin{array}{c}-0.33 \\
(-0.60,-0.05)\end{array}$ & .020 & 1792 & $\begin{array}{c}-0.03 \\
(-0.11,0.05)\end{array}$ & .470 & 1824 & $\begin{array}{c}-0.31 \\
(-0.54,-0.07)\end{array}$ & .011 & 1796 & $\begin{array}{c}-0.14 \\
(-0.27,-0.01)\end{array}$ & .032 & 1806 & $\begin{array}{c}-0.19 \\
(-0.36,-0.02)\end{array}$ & .026 & 1807 \\
\hline Fully Adjusted & $\begin{array}{c}-0.32 \\
(-0.60,-0.03)\end{array}$ & .030 & 1792 & $\begin{array}{c}-0.02 \\
(-0.11,0.07)\end{array}$ & .675 & 1824 & $\begin{array}{c}-0.31 \\
(-0.56,-0.06)\end{array}$ & .014 & 1796 & $\begin{array}{c}-0.13 \\
(-0.26,0.01) \\
\end{array}$ & .065 & 1806 & $\begin{array}{c}-0.20 \\
(-0.37,-0.02)\end{array}$ & .027 & 1807 \\
\hline \multicolumn{16}{|l|}{ Young Person Sample } \\
\hline \multicolumn{16}{|l|}{ Anxiety } \\
\hline Unadjusted & $\begin{array}{c}0.18 \\
(-0.07,0.42)\end{array}$ & .158 & 1823 & $\begin{array}{c}0.05 \\
(-0.04,0.13)\end{array}$ & .274 & 1848 & $\begin{array}{c}0.11 \\
(-0.10,0.32)\end{array}$ & .305 & 1827 & $\begin{array}{c}0.06 \\
(-0.05,0.18)\end{array}$ & .293 & 1846 & $\begin{array}{c}0.11 \\
(-0.05,0.26)\end{array}$ & .178 & 1826 \\
\hline Fully Adjusted & $\begin{array}{c}0.15 \\
(-0.10,0.40)\end{array}$ & .252 & 1823 & $\begin{array}{c}0.04 \\
(-0.04,0.13)\end{array}$ & .318 & 1848 & $\begin{array}{c}0.08 \\
(-0.13,0.29)\end{array}$ & .455 & 1827 & $\begin{array}{c}0.05 \\
(-0.07,0.17) \\
\end{array}$ & .386 & 1846 & $\begin{array}{c}0.09 \\
(-0.07,0.25)\end{array}$ & .283 & 1826 \\
\hline
\end{tabular}

Preprint (Version 2): 15th November 2021. This paper has not been peer reviewed. 


\begin{tabular}{|c|c|c|c|c|c|c|c|c|c|c|c|c|c|c|c|}
\hline \multicolumn{16}{|l|}{ Depression } \\
\hline Unadjusted & $\begin{array}{c}0.20 \\
(-0.05,0.46)\end{array}$ & .113 & 1823 & $\begin{array}{c}-0.01 \\
(-0.09,0.07)\end{array}$ & .812 & 1848 & $\begin{array}{c}0.19 \\
(-0.02,0.41)\end{array}$ & .079 & 1827 & $\begin{array}{c}0.08 \\
(-0.04,0.19)\end{array}$ & .213 & 1846 & $\begin{array}{c}0.11 \\
(-0.05,0.27)\end{array}$ & .173 & 1826 \\
\hline Fully Adjusted & $\begin{array}{c}0.16 \\
(-0.10,0.42)\end{array}$ & .218 & 1823 & $\begin{array}{c}-0.02 \\
(-0.10,0.07)\end{array}$ & .706 & 1848 & $\begin{array}{c}0.16 \\
(-0.06,0.38)\end{array}$ & .162 & 1827 & $\begin{array}{c}0.06 \\
(-0.07,0.18)\end{array}$ & .364 & 1846 & $\begin{array}{c}0.09 \\
(-0.07,0.25)\end{array}$ & .285 & 1826 \\
\hline \multicolumn{16}{|l|}{ Wellbeing } \\
\hline Unadjusted & $\begin{array}{c}-0.29 \\
(-0.54,-0.04)\end{array}$ & .025 & 1823 & $\begin{array}{c}-0.00 \\
(-0.08,0.08)\end{array}$ & .979 & 1848 & $\begin{array}{c}-0.27 \\
(-0.48,-0.06)\end{array}$ & .013 & 1827 & $\begin{array}{c}-0.13 \\
(-0.25,-0.02)\end{array}$ & .025 & 1846 & $\begin{array}{c}-0.14 \\
(-0.30,0.02)\end{array}$ & .077 & 1826 \\
\hline Fully Adjusted & $\begin{array}{c}-0.26 \\
(-0.53,-0.00)\end{array}$ & .048 & 1823 & $\begin{array}{c}0.00 \\
(-0.09,0.09)\end{array}$ & .993 & 1848 & $\begin{array}{c}-0.24 \\
(-0.47,-0.02)\end{array}$ & .031 & 1827 & $\begin{array}{c}-0.12 \\
(-0.25,-0.00)\end{array}$ & .049 & 1846 & $\begin{array}{c}-0.13 \\
(-0.30,0.03)\end{array}$ & .121 & 1826 \\
\hline
\end{tabular}

Note. Linear regressions. $b=$ unstandardised beta coefficient. CI = confidence interval. Polygenic risk scores were created using the p-value threshold of 0.05 . Fully adjusted models $=$ adjusted for genetic principal components of ancestry (PC1-PC10). 


\section{Figure 1}

Cross-Sectional Associations between COVID-19 Holistic Risk Perceptions and Mental

Health, Wellbeing, and Risk Behaviours

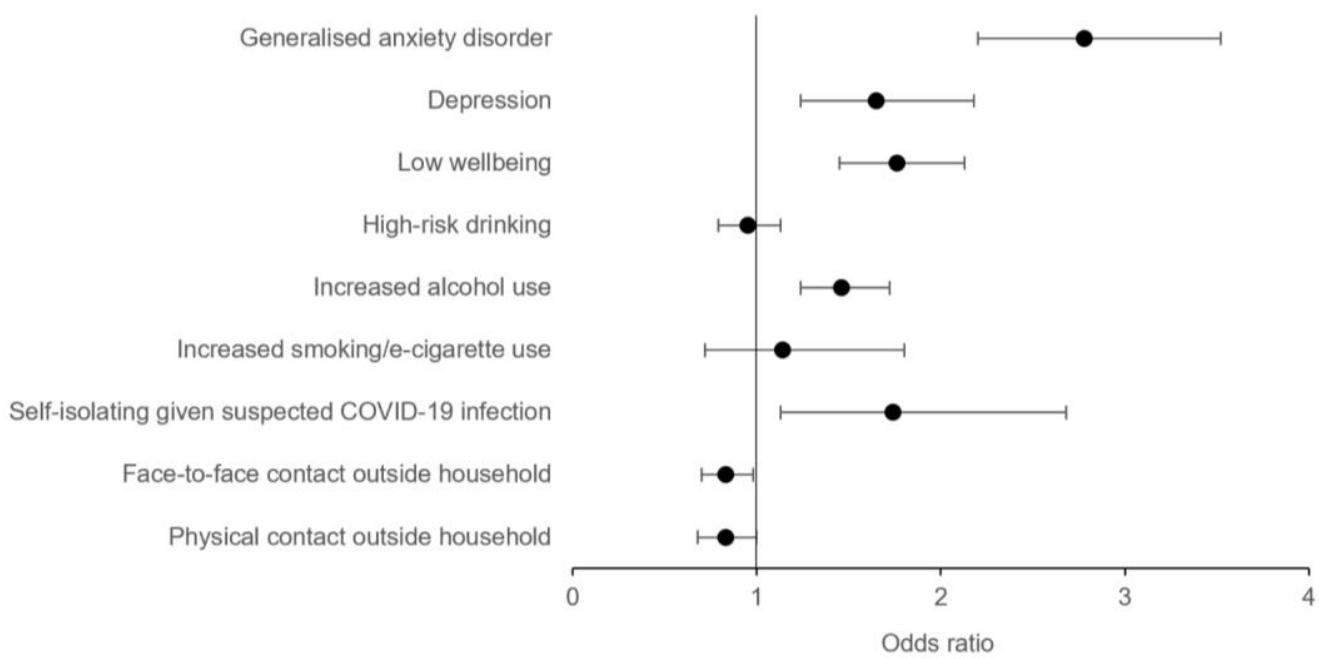

Note. Whole sample. Forest plot shows the fully adjusted odds ratios (circles) and $95 \%$ confidence intervals (bars). Fully adjusted $=$ adjusted for age, gender, education, keyworker status, pre-pandemic anxiety, depression, high-risk drinking, smoking, and early pandemic suspected COVID-19 infection.

Preprint (Version 2): 15th November 2021. This paper has not been peer reviewed. 


\section{Figure 2}

Longitudinal Associations between Pre-pandemic and Early Pandemic Variables and COVID-19 Holistic Risk Perceptions

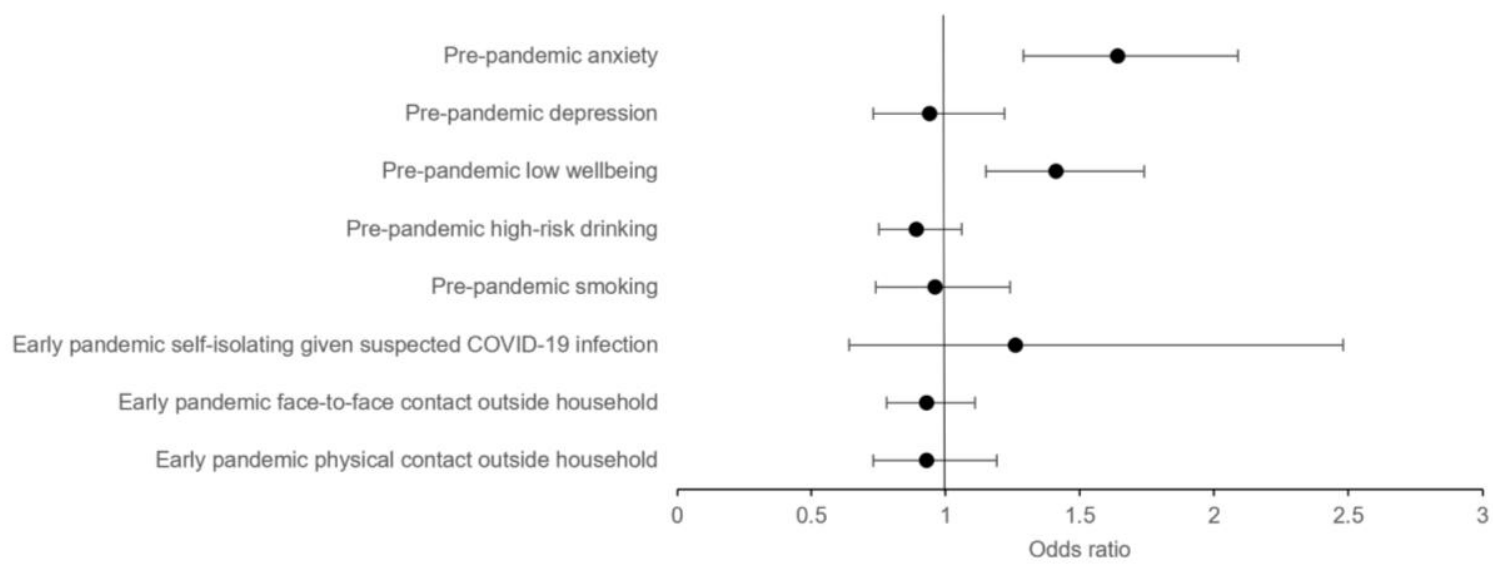

Note. Whole sample. Forest plot shows the fully adjusted odds ratios (circles) and $95 \%$ confidence intervals (bar). Fully adjusted = adjusted for age, gender, education, keyworker status, pre-pandemic anxiety, depression, high-risk drinking, smoking, and early pandemic suspected COVID-19 infection.

Preprint (Version 2): 15th November 2021. This paper has not been peer reviewed. 